\title{
Research on Coordination Complexity of E-Commerce Logistics Service Supply Chain
}

\author{
Yaoguang Zhong, ${ }^{1}$ Fangfang Guo, ${ }^{1}$ Huajun Tang $\mathbb{D},{ }^{2}$ and Xumei Chen $\mathbb{D}^{3}$ \\ ${ }^{1}$ School of Economics and Management, Dongguan University of Technology, Guangdong 523808, China \\ ${ }^{2}$ School of Business, Macau University of Science and Technology, Macau 999078, China \\ ${ }^{3}$ School of Traffic and Transportation, Beijing Jiaotong University, Beijing 100044, China \\ Correspondence should be addressed to Huajun Tang; hjtang@must.edu.mo
}

Received 16 February 2020; Revised 26 March 2020; Accepted 31 March 2020; Published 28 April 2020

Guest Editor: Baogui Xin

Copyright ( 2020 Yaoguang Zhong et al. This is an open access article distributed under the Creative Commons Attribution License, which permits unrestricted use, distribution, and reproduction in any medium, provided the original work is properly cited.

\begin{abstract}
With the rapid growth of E-commerce business, logistics service, especially the last-mile distribution, has become one bottleneck, which leads to the rise of coordination complexity of logistics service supply chain (LSSC). This research, based on Stackelberg's game theory, studies the coordination of a new three-echelon LSSC consisting of an E-commerce mall, an express company, and a terminal distribution service provider and investigates the optimal solutions and profits for each party within the semicentralized and centralized LSSC alliances, respectively. To accomplish this, it firstly shows that the three-echelon LSSC can lead to global optimum under the centralized decision-making scenario and then deploys the contract coordination schemes, including revenue sharing, cost sharing, and unit delivery price contracts, in three semicentralized alliances, so as to achieve the same performance of the centralized decision-making scenario, in which each party in the LSSC can achieve the win-win situation. Finally, numerical examples are provided to illustrate the feasibility and the effectiveness of the proposed coordination strategies. This study enriches the coordination theory in the field of LSSC and provides managerial insights for decision makers in LSSC.
\end{abstract}

\section{Introduction}

In recent years, the booming development of E-commerce in China is promoting the rapid growth of the logistics express industry. According to the data of the State Post Office in 2019, the national express business revenue reached RMB745 billion with an annual increase of $23 \%$, and the total express business volume exceeded 63 billion pieces with an increase of $24 \%$. However, the lag of logistics and distribution services has been seriously mismatched with the development of E-commerce, which has become one of the main complaints of online shopping consumers. Logistics and distribution, especially the terminal last-mile distribution, has become the bottleneck of the development of E-commerce business [1]. Hence, it is urgent to coordinate logistics service supply chain (LSSC) so as to improve the service level and keep E-commerce industry sustainable.
Spengler [2] was the first to introduce the idea of supply chain coordination and proved that a double marginalization effect naturally led to a suboptimal supply chain. Supply chain coordination aims to provide a win-win mechanism to stimulate all the partners in the supply chain to cooperate together. Recently, supply chain coordination has been one popular topic in the field of supply chain management. The main research streams for this topic focus on all kinds of supply chain coordination strategies, including buyback contract, revenue sharing contract, cost sharing contract, sales rebate policy, quantity flexibility scheme, and quantity discount contract [3]. For instance, Luo and Chen [4] studied the retailer's optimal order policy and the supplier's optimal production policy under revenue sharing contract. Xie et al. [3] integrated the revenue sharing contract in the forward channel with the cost sharing contract and deployed the Stackelberg game to investigate the contract coordination mechanism. Most recently, Zhao et al. [5] focused on 
the combination of a buy-back contract and a revenue sharing contract so as to improve the efficiency of a supply chain. However, most existing literatures mainly focus on the coordination of upstream partners (e.g., supplier or manufacturer) and downstream partners (e.g., retailer). There is a lack of literature in studying about this topic in the field of terminal distribution. Hence, there is a need to study the coordination of LSSC, including E-commerce mall, express company, and terminal distribution provider.

The aim of this study is to propose several coordination strategies, including revenue sharing scheme, cost sharing contract, and coordination of unit delivery price, in order to make three semicentralized alliances achieve the global optimal performance under centralized decision-making scenario. The results of this research suggest that all the three schemes, based on Stackelberg's game theory, can help the whole LSSC realize the win-win status. The contribution of this work enriches the supply chain coordination in the field of downstream three-echelon LSSC including the terminal distribution, takes the price and effort level of logistics service dependent demand into account, develops effective coordination strategies, such as revenue sharing and cost sharing contracts, and unit delivery price coordination, and provides managerial insights for decision makers to choose appropriate alliance in real business.

The structure of this study is as follows. In Section 2, the main literatures related to the research topic are reviewed. In Section 3, the research problem and decision models are proposed. In Section 4, semicentralized and centralized LSSC decision models are put forward. In Section 5, the coordination schemes in different alliances are derived: revenue sharing, cost sharing, and coordination of the unit delivery price. Section 6 provides numerical analysis to test the feasibility of the coordination strategies. Section 7 summarizes the research, provides management suggestions, and puts forward the limitations of this study for future research.

\section{Literature Review}

There exist various literatures on supply chain coordination. The research object ranges from the two-echelon supply chain composed of manufacturers and retailers, to the purchasing and retailing supply chain composed of manufacturers, online retailers, and the third-party logistics (3PL), and then to the LSSC system including E-commerce malls, express companies, and terminal distribution service providers. For the sake of clarity, two main stream of literatures on analytical methods and supply chain coordination are reviewed, respectively.

There always exist one leader and his followers in a supply chain, in which the leader can obtain the followers' optimal decision and then make his own optimal decision. Hence, game theory is widely applied in existing literatures. For instance, Luo and Chen [4] studied the role of revenue sharing contracts in the coordination of supply chains with random yield and stochastic market demand. With game theory, they derived the retailer's optimal order decision and the supplier's optimal production policy under revenue sharing contracts. Wu et al. [6] deployed game theory to study the coordination of supply chain pricing and advertising decision taking into account the impact of platform users on demand. The results showed that the coordination of supply chain based on the revenue sharing contract can improve the total supply chain performance. Song and Gao [7] constructed game models under centralized and decentralized scenarios, based on revenue sharing contracts. The results showed that revenue sharing contract can effectively improve the greening level of products and the overall profitability of supply chain. Xie et al. [3] combined the revenue sharing contract in the forward channel with the channel investment cost sharing contract and introduced the Stackelberg game to investigate the contract coordination mechanism. Yan et al. [8] used game theory to study the pricing strategy in a dual channel supply chain consisting of a supplier with limited capital and an e-retailer providing capital. Hua et al. $[9,10]$ proposed four games to investigate the optimal pricing strategy in a two-echelon reverse supply chain.

As for supply chain coordination, there are various existing studies with the following perspectives:

(1) Quantity discount perspective. For instance, Pang et al. [11] studied the coordination role of revenue sharing contract in a three-echelon supply chain including manufacturers, distributors, and retailers and proposed an improved revenue sharing contract based on quantity discount policy. Pang et al. [12] proposed an improved revenue sharing contract based on quantity discount strategy. Taleizadeh et al. [13] deployed quantity discount policies in the coordination of a two-echelon supply chain in presence of market segmentation and credit payment.

(2) Demand perspective. Sang [14] studied the revenue sharing contract of multilevel supply chain with customer demand and retail price as fuzzy variables and proposed a revenue sharing contract with fuzzy demand and information asymmetry. Zhao et al. [5] studied the effect of joint buyback and revenue sharing contracts on supply chain coordination between risk neutral suppliers and risk averse retailers under stochastic demand. Cai et al. [15] designed a flexible contract for VMI supply chain with service-sensitive demand. Zhao et al. [16] investigated the coordination of fuzzy closed-loop supply chain, in which demand was price-dependent and information was asymmetric.

(3) Resource-constrained perspective. Zhao et al. [17] established a model consisting of manufacturer and capital constrained retailer and studied the pricing and the coordination of green supply chain with capital constraint. Yan et al. [18] analyzed the coordination feasibility with supply chain financing and concluded that the financing solution with a suitable combination of decision preferences can realize the coordination. Furthermore, Yan et al. [8] investigated the pricing coordination strategy in a dual-channel supply chain including one capital- 
constrained supplier and one e-retailer providing finance.

(4) Supply chain partner perspective. Many scholars focused on two-echelon supply chain in the research of supply chain coordination. For example, Zhang et al. [19] constructed a supply chain model with one manufacturer and one retailer for deteriorating items, in which they designed a revenue sharing and cooperative investment contract. Bai et al. [20] studied a two-phase sustainable supply chain system composed of producers and retailers and the revenue coordination under carbon emission cap and trade control. Giri et al. [21] proposed a two-stage closed-loop supply chain game model consisting of a manufacturer and a retailer to coordinate the performance of the supply chain through revenue sharing contracts. Heydari and Ghasemi [22] investigated a two-echelon reverse supply chain (RSC) consisting of a single remanufacturer and a single collector. Peng et al. [23] used Stackelberg model to explore a supply chain composed of suppliers and manufacturers and studied the production, price, and carbon emission reduction decisions of decentralized and centralized supply chain. Zou et al. [24] constructed a sustainable closed-loop supply chain coordination mechanism consisting of one manufacturer and two retailers competing in price to coordinate the profits of supply chain members through revenue sharing contracts. Mohammadi et al. [25] studied the supply chain composed of a single supplier and a single vendor and proposed new revenue and preservation technology investment sharing coordination contract based on the fresh supply chain coordination mechanism. Ghazanfari et al. [26] used two different methods to model the supply chain composed of supplier and buyer based on the Stackelberg game model: (1) the traditional selling cycle in the open market without considering the government's incentives and (2) the modern selling cycle in the organized market considering the government's incentives. There also exist some studies on the multiechelon supply chain. For instance, Zhong et al. [27] expanded from a two-level supply chain composed of an E-commerce platform and a logistics service provider to a three-level supply chain composed of an E-commerce platform, an express company, and a terminal distributor and studied the profit distribution scheme based on revenue sharing contract in the e-commerce environment. Pang et al. [28] studied the revenue coordination of a three-stage supply chain consisting of a manufacturer, a distributor, and a retailer. Hou et al. [29] focused on a three-echelon supply chain composed of a manufacturer, a distributor, and a retailer for a single selling period. Based on a revenue sharing contract, the coordination of the decentralized supply chain with the simultaneous move game or the leader-follower game was analyzed. Yuan et al. [30] constructed a three-tier seafood online retail logistics service supply chain LSSC including online retailers, logistics service integrators, and functional logistics service providers. Liu and Yi [31] constructed a threestage supply chain coordination strategy consisting of a manufacturer, a retailer, and a data company and analyzed four benefit models of BDI investment in the decentralized and centralized supply chain. Giri and Sarker [32] studied the contract coordination of a three-level supply chain system, which is composed of a raw material supplier, a manufacturer, and a retailer.

(5) Policy perspective. In addition, some researchers took the related policy into account. For example, Liu et al. [33] analyzed the coordination between supply chains and retailers through revenue sharing contracts under the government price control policy after the demand disruption of oil, natural gas, and agricultural products which were subject to government price restrictions. Meng et al. [34] established an agent-based revenue sharing negotiation model to study the complexity of stakeholders' revenue sharing in time compression of construction projects.

In summary, the above literatures mainly focus on the traditional production or retailing supply chain or logistics supply chain, but it involves less coordination between the E-commerce mall and logistics service providers. The existing coordination mechanisms mainly included revenue sharing and cost sharing, but seldom involves the coordination of unit delivery price. In the supply chain coordination, most of the literatures focused on the coordination between centralized decision-making and decentralized decision-making. However, as online shopping has become a popular trend, the relationship between E-commerce malls and logistics service providers tends to be closer. Hence, the purpose of this research is to establish three semicentralized alliances in the three-echelon down-stream supply chain consisting of E-commerce mall, express company, and terminal distribution service company and design some reasonable coordination strategies so as to make all the supply chain partners achieve the win-win situation. Table 1 lists some key-related literatures.

\section{Problem Description and Research Models}

3.1. Problem Description. The logistics service supply chain (LSSC) in this study includes an E-commerce mall, an express company, and a terminal distribution service provider. The E-commerce mall purchases products and sells them online to customers. The express company is responsible for carrying products to terminal distribution service provider network, and the terminal distribution service provider is responsible for delivering them to final customers. Each partner in the LSSC has to make some decision. The E-commerce mall should determine the selling price, the express company should determine the unit price of transportation service and the effort level of logistics service, and the terminal distribution service provider should determine the unit delivery price so as to make their own profit optimal. The problem of this work is how to develop appropriate coordination strategies to stimulate all the partners to cooperate together and achieve the all-win situation. 
TABLE 1: List of key-related literatures.

\begin{tabular}{|c|c|c|c|c|c|}
\hline \multirow{2}{*}{$\begin{array}{l}\text { Author(s) and } \\
\text { Ref. no. }\end{array}$} & \multirow{2}{*}{$\begin{array}{c}\text { Journal Title and } \\
\text { Year }\end{array}$} & \multicolumn{4}{|c|}{ Factors considered in the research problems } \\
\hline & & Supply chain partners & Coordination strategy & Supply chain system & Demand \\
\hline Pang et al. [11] & $\begin{array}{l}\text { Discrete Dynamics } \\
\text { in Nature and } \\
\text { Society, } 2014\end{array}$ & $\begin{array}{l}\text { A supplier, and a } \\
\text { manufacturer }\end{array}$ & Revenue sharing & $\begin{array}{l}\text { Decentralized and } \\
\text { centralized }\end{array}$ & $\begin{array}{l}\text { Sales effort } \\
\text { dependent }\end{array}$ \\
\hline $\begin{array}{l}\text { Heydari and } \\
\text { Ghasemi [22] }\end{array}$ & $\begin{array}{l}\text { Journal of Cleaner } \\
\text { Production, } 2018\end{array}$ & $\begin{array}{l}\text { A remanufacturer and a } \\
\text { collector }\end{array}$ & Revenue sharing & $\begin{array}{l}\text { Decentralized and } \\
\text { centralized }\end{array}$ & Stochastic \\
\hline Liu and Yi [31] & $\begin{array}{l}\text { Annals of Operation } \\
\text { Research, } 2018\end{array}$ & $\begin{array}{l}\text { A manufacturer, a retailer, } \\
\text { and a data company }\end{array}$ & Revenue sharing & $\begin{array}{l}\text { Decentralized and } \\
\text { centralized }\end{array}$ & Stochastic \\
\hline $\begin{array}{l}\text { Mohammadi } \\
\text { et al. [25] }\end{array}$ & $\begin{array}{l}\text { Journal of Cleaner } \\
\text { Production, } 2019\end{array}$ & A supplier and a buyer & $\begin{array}{l}\text { Revenue-and- } \\
\text { preservation- } \\
\text { technology- } \\
\text { investment-sharing }\end{array}$ & $\begin{array}{l}\text { Decentralized and } \\
\text { centralized }\end{array}$ & $\begin{array}{l}\text { Retail price and } \\
\text { freshness degree of } \\
\text { products dependent }\end{array}$ \\
\hline $\begin{array}{l}\text { Ghazanfari } \\
\text { et al. [26] }\end{array}$ & $\begin{array}{l}\text { IEEE Transactions } \\
\text { on Engineering } \\
\text { Management, } 2019\end{array}$ & A supplier and a buyer & $\begin{array}{l}\text { Short-term tax breaks } \\
\text { and a single-window } \\
\text { system }\end{array}$ & $\begin{array}{l}\text { Traditional selling } \\
\text { cycle and modern } \\
\text { selling cycle }\end{array}$ & $\begin{array}{l}\text { Stochastic } \\
\text { multifactor- } \\
\text { dependent }\end{array}$ \\
\hline $\begin{array}{l}\text { Zeng and Hou, } \\
{[35]}\end{array}$ & $\begin{array}{l}\text { International Journal } \\
\text { of Production } \\
\text { Economics, } 2019\end{array}$ & $\begin{array}{l}\text { A supplier and a } \\
\text { distributor }\end{array}$ & Quantity discount & $\begin{array}{l}\text { Decentralized and } \\
\text { centralized }\end{array}$ & Price-dependent \\
\hline Ye et al. [36] & $\begin{array}{c}\text { Operational } \\
\text { Research, } 2020\end{array}$ & $\begin{array}{l}\text { An agribusiness firm and } \\
\text { multiple risk-averse } \\
\text { farmers }\end{array}$ & $\begin{array}{c}\text { Revenue sharing, } \\
\text { production cost } \\
\text { sharing, guaranteed } \\
\text { money }\end{array}$ & $\begin{array}{l}\text { Decentralized and } \\
\text { centralized }\end{array}$ & Stochastic \\
\hline Zhao et al. [37] & $\begin{array}{c}\text { European Journal of } \\
\text { Operational } \\
\text { Research, } 2020\end{array}$ & $\begin{array}{l}\text { Two manufacturers and a } \\
\text { major retailer }\end{array}$ & $\begin{array}{l}\text { Revenue sharing } \\
\text { consignment }\end{array}$ & $\begin{array}{l}\text { Decentralized and } \\
\text { centralized }\end{array}$ & $\begin{array}{l}\text { Shelf space and sales } \\
\text { price dependent }\end{array}$ \\
\hline This study & & $\begin{array}{l}\text { E-commerce mall, express } \\
\text { company, terminal } \\
\text { distribution service } \\
\text { provider }\end{array}$ & $\begin{array}{l}\text { Revenue sharing, cost } \\
\text { sharing, unit delivery } \\
\text { price }\end{array}$ & $\begin{array}{l}\text { Semicentralized and } \\
\text { centralized }\end{array}$ & $\begin{array}{c}\text { Sales price- } \\
\text { dependent, effort } \\
\text { level of logistics } \\
\text { service dependent }\end{array}$ \\
\hline
\end{tabular}

3.2. Symbol Description. The basic symbols and descriptions are defined in Table 2.

\subsection{Assumption and Models}

(1) All the members in LSSC are risk neutral

(2) All the members are rational who make their own decisions to maximize their own profit

(3) The product demand is affected by the price and the effort level of logistics service [27]

(4) The cost function of logistics service effort is defined as $g(s)=k s^{2}$ [38], which is the cost paid by logistics service providers to improve the efficiency of logistics service in order to satisfy customers and increase product sales, where $k>0$ represents the effort cost coefficient of logistics services

This study includes an E-commerce mall $M$, an express company $E$, and a terminal distribution service provider $T$. Based on Chiang et al. and Huang's linear demand functions $[39,40]$, it is assumed that the E-commerce mall sells only one product and the terminal distribution service provider cost is borne by the E-commerce mall, which is in line with the reality that Tmall subsidizes the Cainiao station. The E-commerce mall plays a dominant role in the supply chain, and the market demand $Q$ is affected by the price $p$ and the effort level of logistics service $s$, which decreases with the
TABLE 2: Symbols and descriptions of research models.

\begin{tabular}{lc}
\hline Symbols & Descriptions \\
\hline $\mathrm{q}$ & Market demand for product \\
$Q_{0}$ & Market base demand for product \\
$\alpha$ & The elasticity coefficient of market demand to price \\
$\beta$ & The elasticity coefficient of market demand to logistics \\
$p$ & service \\
$s$ & Selling price of E-commerce product \\
$k$ & Effort level of logistics service \\
$\Delta \mathrm{p}$ & Marginal profit of E-commerce mall or alliances \\
$\eta$ & Cost sharing ratio \\
$C_{M}$ & Unit cost of procurement and operation for E- \\
$C_{E}$ & commerce product \\
$C_{T}$ & Unit cost of express company \\
$\mathrm{g}(s)$ & Service cost of logistics service provider \\
$W_{E}$ & Unit price of express company \\
$W_{T}$ & Unit price of terminal distribution service provider \\
$W_{E T}$ & Service quotation of express company and terminal \\
$\theta$ & distribution service provider alliance \\
$\varphi$ & Revenue sharing ratio \\
\hline
\end{tabular}

increasing price and increases with the effort level of logistics service. Suppose the relationship among the three is $Q=$ $Q_{0}-\alpha p+\beta s$ and $Q_{0}>0, \alpha>0$, and $\beta>0$. According to the 
market demand, the suppliers decide the order quantity and assuming that there is no shortage.

The express company determines its own effort level of logistics service $s$, whose unit operating cost is $C_{E}$ and unit service price is $W_{E}$. Assuming there are no capacity restrictions, it can meet any service requirements, but it must pay the corresponding incremental operating costs. The unit operating cost of the terminal distribution service provider is $C_{T}$, and the unit price of service is $W_{T}$. In order to ensure the decision variables $p, s, W_{E}$, and $W_{T}$ are positive, the relationship between variables is satisfied that $2 \alpha k-\beta^{2}>0$ and $Q_{0}-\alpha\left(C_{M}+C_{E}+C_{T}\right)>0$.

The market demand of the product is

$$
Q=Q_{0}-\alpha p+\beta s \text {. }
$$

The profit of the E-commerce mall is

$$
\prod_{M}=\left(p-C_{M}-W_{E}-W_{T}\right) q .
$$

The profit of the express company is

$$
\prod_{E}=\left(W_{E}-C_{E}\right) q-g(s)=\left(W_{E}-C_{E}\right) q-k s^{2} .
$$

The profit of the terminal distribution service provider is

$$
\prod_{T}=\left(W_{T}-C_{T}\right) q .
$$

The profit of the E-commerce mall and the terminal distribution service provider alliance is

$$
\prod_{M T}=\left(p-W_{E}-C_{M}-C_{T}\right) q
$$

The profit of the E-commerce mall and the express company is

$$
\prod_{M E}=\left(p-W_{T}-C_{M}-C_{E}\right) q-k s^{2} .
$$

The profit of the express company and the terminal distribution service provider alliance is

$$
\prod_{E T}=\left(W_{E T}-C_{E}-C_{T}\right) q-k s^{2}
$$

The system profit is

$$
\begin{aligned}
\prod=\prod_{M}+\prod_{E}+\prod_{T} & =\left(p-C_{M}-C_{E}-C_{T}\right) q-g(s) \\
& =\left(p-C_{M}-C_{E}-C_{T}\right) q-k s^{2} .
\end{aligned}
$$

\section{Semicentralized and Centralized Decision Models}

In this study, the E-commerce mall is the main leader, and the express company and the terminal distribution service provider are the followers. Based on Stackelberg's game theory, the E-commerce mall determines the unit price of the product $p$ and then the express company decides the unit price of transportation service $W_{B}$ and the effort level of logistics service $s$, and the terminal distribution service provider determines the unit delivery price $W_{C}$ [28].

4.1. Semicentralized Decision Models. In the case of semicentralized decision-making, the LSSC consists of one alliance and another partner, in which the alliance includes the other two partners. There are three situations below:

Semicentralized Model 1. The E-commerce mall and the terminal distribution service provider form an alliance, which is equivalent to the self-operated terminal network of the E-commerce mall

Semicentralized Model 2. The E-commerce mall and the express company form an alliance, which is equivalent to the self-operated distribution of the E-commerce mall

Semicentralized Model 3. The express company and the terminal distribution service provider form an alliance, which is equivalent to the whole process of the express company from the E-commerce warehouse to the customer

4.1.1. Decision Analysis of Semicentralized Model 1. The E-commerce mall and the terminal distribution service provider form an alliance, which is equivalent to the selfoperated terminal network of the E-commerce mall. In this case, the alliance is the leader and the express company is the follower. In the first stage, the alliance determines the selling price of its product $p$ according to the market information so as to maximize its own profit. In the second stage, the express company decides the best express service price $W_{B}$ and the effort level of logistics service $s$ according to the market information and the information provided by the alliance.

In order to ensure that the E-commerce alliance is profitable, there is

$$
p=C_{M}+W_{E}+W_{T}+\Delta p .
$$

Then, the objective functions of the alliance and the express company are

$$
\left\{\begin{array}{l}
\max \Pi_{\mathrm{E}}=\left(\mathrm{W}_{\mathrm{E}}-\mathrm{C}_{\mathrm{E}}\right)\left[\mathrm{Q}_{0}-\alpha\left(\mathrm{C}_{\mathrm{M}}+\mathrm{C}_{\mathrm{E}}+\mathrm{W}_{\mathrm{E}}+\Delta \mathrm{p}\right)+\beta \mathrm{s}\right]-k s^{2}, \\
\max \Pi_{\mathrm{MT}}=\left(\mathrm{p}-\mathrm{C}_{\mathrm{M}}-\mathrm{W}_{\mathrm{E}}-\mathrm{C}_{\mathrm{T}}\right)\left[\mathrm{Q}_{0}-\alpha\left(\mathrm{C}_{\mathrm{M}}+\mathrm{C}_{\mathrm{T}}+\mathrm{W}_{\mathrm{E}}+\Delta \mathrm{p}\right)+\beta \mathrm{s}\right] .
\end{array}\right.
$$


Use the reverse induction method to solve the problem. First, solving the first partial derivatives of $W_{E}$ and $s$ about $\prod_{E}$ in formula (10) is

$$
\begin{aligned}
& \frac{\partial \prod_{E}}{\partial W_{E}}=Q_{0}-\alpha\left(C_{M}-C_{E}+C_{T}+\Delta p\right)+\beta s-2 \alpha W_{E}, \\
& \frac{\partial \prod_{E}}{\partial s}=\beta\left(W_{E}-C_{E}\right)-2 k s .
\end{aligned}
$$

The second-order partial derivative of $W_{E}$ and $s$ about $\prod_{E}$ in formula (10) is

$$
\begin{aligned}
& \frac{\partial^{2} \prod_{E}}{\partial W_{E}^{2}}=-2 a<0, \\
& \frac{\partial^{2} \prod_{E}}{\partial s^{2}}=-2 k<0 .
\end{aligned}
$$

The Hessian matrix is $H=\left(\begin{array}{cc}-2 \alpha & \beta \\ \beta & -2 k\end{array}\right)$, whose firstorder determinant $\left|H_{1}\right|=-2 \alpha<0$ and $\left|H_{2}\right|=4 \alpha k-\beta^{2}>0$. It is shown that the Hessian matrix is negative definite, and there is a unique optimal $\left(W_{E}, s\right)$, leading the $\prod_{E}$ to be maximum.

$$
\begin{aligned}
& \text { Let }\left(\partial \prod_{E} / \partial W_{E}\right)=0 \text { and }\left(\partial \prod_{E} / \partial s\right)=0 \text {, then } \\
& \qquad \begin{array}{l}
W_{E}=\frac{Q_{0}-\alpha\left(C_{M}-C_{E}+C_{T}+\Delta p\right)+\beta s}{2 \alpha}, \\
s=\frac{\beta\left(W_{E}-C_{E}\right)}{2 k} .
\end{array}
\end{aligned}
$$

Integrate equations (13) and (14), we get the expressions of $W_{E}$ and $s$ for $\Delta p$ as follows:

$$
\left\{\begin{array}{l}
\mathrm{W}_{\mathrm{E}}=\frac{2 \mathrm{k}\left[\mathrm{Q}_{0}-\alpha\left(\mathrm{C}_{\mathrm{M}}-\mathrm{C}_{\mathrm{T}}+\Delta \mathrm{p}\right)\right]+\left(2 \alpha \mathrm{k}-\beta^{2}\right) C_{\mathrm{B}}}{4 \alpha \mathrm{k}-\beta^{2}} \\
s=\frac{\beta\left[\mathrm{Q}_{0}-\alpha\left(\mathrm{C}_{\mathrm{M}}+\mathrm{C}_{\mathrm{E}}+\mathrm{C}_{\mathrm{T}}+\Delta \mathrm{p}\right)\right]}{4 \alpha \mathrm{k}-\beta^{2}}
\end{array}\right.
$$

Bring equation (15) into equation (14), then

$$
\prod_{M T}=\Delta P \frac{2 \alpha k\left[Q_{0}-\alpha\left(C_{M}+C_{E}+C_{T}+\Delta p\right)\right]}{4 \alpha k-\beta^{2}} .
$$

Then, the first partial derivative of $\Delta p$ about $R_{A C}$ in formula $(16)$ is $\left(\partial \prod_{M T} / \partial \quad \Delta p\right)=\left(\left(2 \alpha k\left[Q_{0}-a\left(C_{M^{+}}\right.\right.\right.\right.$ $\left.\left.\left.\left.C_{E}+C_{T}+2 \Delta p\right)\right]\right) / 4 \alpha k-\beta^{2}\right)$. The second-order partial derivative is $\left(\partial^{2} \prod_{M T} / \partial \Delta p^{2}\right)=\left(-4 \alpha^{2} k / 4 \alpha k-\beta^{2}\right)<0$. This implies that $\prod_{M T}$ is the concave function about $\Delta p$, so there is only one $\Delta p$ that makes the $\prod_{M T}$ optimal. Let $\left(\partial \prod_{M T} / \partial \Delta p\right)=0$, then

$$
\Delta p=\frac{Q_{0}-\alpha\left(C_{M}+C_{E}+C_{T}\right)}{2 \alpha} .
$$

Bring equation (17) into equation (15), then

$$
\begin{aligned}
W_{E 1}^{*} & =\frac{k\left[Q_{0}-\alpha\left(C_{M}+C_{T}\right)\right]+\left(3 \alpha k-\beta^{2}\right) C_{E}}{4 \alpha k-\beta^{2}}, \\
s_{1}^{*} & =\frac{\beta\left[Q_{0}-\alpha\left(C_{M}+C_{E}+C_{T}\right)\right]}{2\left(4 \alpha k-\beta^{2}\right)} .
\end{aligned}
$$

Bring equations (18)-(19) into equations (1) and (9), then

$$
\begin{aligned}
& q_{1}^{*}=\frac{\alpha k\left[Q_{0}-\alpha\left(C_{M}+C_{E}+C_{T}\right)\right]}{4 \alpha k-\beta^{2}}, \\
& p_{1}^{*}=\frac{\left(6 \alpha k-\beta^{2}\right) Q_{0}+\alpha\left(2 \alpha k-\beta^{2}\right)\left(C_{M}+C_{E}+C_{T}\right)}{2 \alpha\left(4 \alpha k-\beta^{2}\right)} .
\end{aligned}
$$

Then, we can get the optimal profit of the alliance, the express company, and the whole system:

$$
\begin{gathered}
\prod_{M T}^{*}=\frac{k\left[Q_{0}-\alpha\left(C_{M}+C_{E}+C_{T}\right)\right]^{2}}{2\left(4 \alpha k-\beta^{2}\right)}, \\
\prod_{E 1}^{*}=\frac{k\left[Q_{0}-\alpha\left(C_{M}+C_{E}+C_{T}\right)\right]^{2}}{4\left(4 \alpha k-\beta^{2}\right)}, \\
\prod_{1}^{*}=\frac{3 k\left[Q_{0}-\alpha\left(C_{M}+C_{E}+C_{T}\right)\right]^{2}}{4\left(4 \alpha k-\beta^{2}\right)} .
\end{gathered}
$$

4.1.2. Decision Analysis of Semicentralized Model 2. The E-commerce mall and the express company form an alliance, which is equivalent to the self-operated distribution of the E-commerce mall. In this case, the alliance is the leader and the terminal distribution service provider is the follower. In the first stage, the alliance decides the selling price $p$ and the effort level of logistics service $s$ according to the market information so as to maximize its own profit. In the second stage, the terminal distribution service provider decides the optimal service price $W_{C}$ according to the market information and the information provided by the alliance.

In order to ensure that the E-commerce alliance is profitable, there is

$$
p=C_{M}+W_{E}+C_{M}+\Delta p .
$$

Then, the objective functions of the alliance and the terminal distribution service provider are

$$
\left\{\begin{array}{l}
\max \Pi_{\mathrm{T}}=\left(\mathrm{W}_{\mathrm{T}}-\mathrm{C}_{\mathrm{T}}\right)\left[\mathrm{Q}_{0}-\alpha\left(\mathrm{C}_{\mathrm{M}}+\mathrm{C}_{\mathrm{E}}+\mathrm{W}_{\mathrm{T}}+\Delta \mathrm{p}\right)+\beta \mathrm{s}\right], \\
\max \Pi_{\mathrm{ME}}=\left(\mathrm{p}-\mathrm{C}_{\mathrm{M}}-\mathrm{C}_{\mathrm{E}}-\mathrm{W}_{\mathrm{T}}\right)\left[\mathrm{Q}_{0}-\alpha\left(\mathrm{C}_{\mathrm{M}}+\mathrm{C}_{\mathrm{E}}+\mathrm{W}_{\mathrm{T}}+\Delta \mathrm{p}\right)+\beta \mathrm{s}\right]-k s^{2} .
\end{array}\right.
$$


Similarly, the corresponding optimal solutions are obtained as follows:

$$
\begin{aligned}
W_{T 2}^{*} & =\frac{2 k\left[Q_{0}-\alpha\left(C_{M}+C_{E}\right)\right]+\left(6 \alpha k-\beta^{2}\right) C_{T}}{8 \alpha k-\beta^{2}}, \\
s_{2}^{*} & =\frac{\beta\left[Q_{0}-\alpha\left(C_{M}+C_{E}+C_{T}\right)\right]}{8 \alpha k-\beta^{2}}, \\
q_{2}^{*} & =\frac{2 \alpha k\left[Q_{0}-\alpha\left(C_{M}+C_{E}+C_{T}\right)\right]}{8 \alpha k-\beta^{2}}, \\
p_{2}^{*} & =\frac{6 k Q_{0}+\left(2 \alpha k-\beta^{2}\right)\left(C_{M}+C_{E}+C_{T}\right)}{8 \alpha k-\beta^{2}}, \\
\prod_{M E}^{*} & =\frac{k\left[Q_{0}-\alpha\left(C_{M}+C_{E}+C_{T}\right)\right]^{2}}{8 \alpha k-\beta^{2}}, \\
\prod_{2}^{*}= & \frac{k\left(12 \alpha k-\beta^{2}\right)\left[Q_{0}-\alpha\left(C_{M}+C_{E}+C_{T}\right)\right]^{2}}{\left(8 \alpha k-\beta^{2}\right)^{2}} . \\
\prod_{T 2}^{*} & =\frac{4 \alpha k^{2}\left[Q_{0}-\alpha\left(C_{M}+C_{E}+C_{T}\right)\right]^{2}}{\left(8 \alpha-\beta^{2}\right)^{2}} \\
&
\end{aligned}
$$

4.1.3. Decision Analysis of Semicentralized Model 3. The express company and the terminal distribution service provider form an alliance, which is equivalent to the whole process of the express company from the E-commerce warehouse to the consumer. In this case, the E-commerce mall is the leader and the alliance is the follower. In the first stage, the E-commerce mall decides the selling price $p$ according to the market information so as to maximize its own profit. In the second stage, the terminal distribution service provider decides the optimal service price $W_{B C}$ and the effort level of logistics service $s$ according to the market information and the information provided by the E-commerce mall.

In order to ensure that the E-commerce alliance is profitable, there is

$$
p=C_{M}+W_{E T}+\Delta p .
$$

Then, the objective functions of the E-commerce mall and the alliance are

$$
\left\{\begin{array}{l}
\max \Pi_{\mathrm{ET}}=\left(\mathrm{W}_{\mathrm{ET}}-\mathrm{C}_{\mathrm{E}}-\mathrm{C}_{\mathrm{T}}\right)\left[\mathrm{Q}_{0}-\alpha\left(\mathrm{C}_{\mathrm{M}}+\mathrm{W}_{\mathrm{ET}}+\Delta \mathrm{p}\right)+\beta \mathrm{s}\right]-k s^{2} \\
\max \Pi_{\mathrm{M}}=\left(\mathrm{p}-\mathrm{C}_{\mathrm{M}}-\mathrm{W}_{\mathrm{ET}}\right)\left[\mathrm{Q}_{0}-\alpha\left(\mathrm{C}_{\mathrm{M}}+\mathrm{W}_{\mathrm{ET}}+\Delta \mathrm{p}\right)+\beta \mathrm{s}\right] .
\end{array}\right.
$$

Similarly, the corresponding optimal solutions are obtained in the following:

$$
\begin{aligned}
W_{E T}^{*} & =\frac{k\left(Q_{0}-\alpha C_{M}\right)+\left(3 \alpha k-\beta^{2}\right)\left(C_{E}+C_{T}\right)}{4 \alpha k-\beta^{2}}, \\
s_{3}^{*} & =\frac{\beta\left[Q_{0}-\alpha\left(C_{M}+C_{E}+C_{T}\right)\right]}{2\left(4 \alpha k-\beta^{2}\right)}, \\
q_{3}^{*} & =\frac{\alpha k\left[Q_{0}-\alpha\left(C_{M}+C_{E}+C_{T}\right)\right]}{4 \alpha k-\beta^{2}}, \\
p_{3}^{*} & =\frac{\left(6 \alpha k-\beta^{2}\right) Q_{0}+\alpha\left(2 \alpha k-\beta^{2}\right)\left(C_{M}+C_{E}+C_{T}\right)}{2 \alpha\left(4 \alpha k-\beta^{2}\right)} \\
\prod_{M 3}^{*} & =\frac{k\left[Q_{0}-\alpha\left(C_{M}+C_{E}+C_{T}\right)\right]^{2}}{2\left(4 \alpha k-\beta^{2}\right)}, \\
\prod_{E T}^{*} & =\frac{k\left[Q_{0}-\alpha\left(C_{M}+C_{E}+C_{T}\right)\right]^{2}}{4\left(4 \alpha k-\beta^{2}\right)}, \\
\prod_{3}^{*}= & \frac{3 k\left[Q_{0}-\alpha\left(C_{M}+C_{E}+C_{T}\right)\right]^{2}}{4\left(4 \alpha k-\beta^{2}\right)} .
\end{aligned}
$$

4.2. Centralized Decision Model. Centralized decisionmaking is similar to the whole process of E-commerce from self-operated products to customers; that is, the E-commerce mall, the express company, and the terminal distribution service provider are regarded as a joint alliance, and their profit maximization is investigated from the perspective of the whole LSSC.

Bring equation (1) into (8), then

$$
\begin{aligned}
& \prod=\left[p-\left(C_{M}+C_{E}+C_{T}\right)\right]\left(Q_{0}-\alpha p+\beta s\right)-k s^{2}, \\
& p_{4}^{*}=\frac{2 k Q_{0}+\left(2 \alpha k-\beta^{2}\right)\left(C_{M}+C_{E}+C_{T}\right)}{4 \alpha k-\beta^{2}}, \\
& s_{4}^{*}=\frac{\beta\left[Q_{0}-\alpha\left(C_{M}+C_{E}+C_{T}\right)\right]}{4 \alpha k-\beta^{2}}, \\
& q_{4}^{*}=\frac{2 \alpha \mathrm{k}\left[Q_{0}-\alpha\left(C_{M}+C_{E}+C_{T}\right)\right]}{4 \alpha k-\beta^{2}} \\
& \prod_{4}^{*}=\frac{k\left[Q_{0}-\alpha\left(C_{M}+C_{E}+C_{T}\right)\right]^{2}}{4 \alpha k-\beta^{2}} .
\end{aligned}
$$

\subsection{Comparative Analysis of Semicentralized and Centralized} Decision Models. In this subsection, three propositions are derived so as to compare the corresponding profit and the effort level of logistics service, order quantity, and selling price between the semicentralized models and the centralized model. 
Proposition 1. The overall profit of centralized decision is better than that of semicentralized decision-making. That is, $\prod_{4}^{*}>\prod_{1}^{*}=\prod_{3}^{*}>\prod_{2}^{*}$ and $\prod_{4}^{*}=(4 / 3) \prod_{1}^{*}$.
It is proved as follows:

$$
\begin{aligned}
\frac{\prod_{4}^{*}}{\prod_{1}^{*}}=\frac{\left(k\left[Q_{0}-\alpha\left(C_{M}+C_{E}+C_{T}\right)\right]^{2} / 4 \alpha k-\beta^{2}\right)}{\left(3 k\left[Q_{0}-\alpha\left(C_{M}+C_{E}+C_{T}\right)\right]^{2} / 4\left(4 \alpha k-\beta^{2}\right)\right)}=\frac{4}{3}>1, \text { so } \prod_{4}^{*}>\prod_{1}^{*} \text { and } \prod_{4}^{*}=(4 / 3) \prod_{1}^{*}, \\
\prod_{1}^{*}-\prod_{2}^{*}=\frac{\beta^{2}\left(16 \alpha k-\beta^{2}\right)\left[Q_{0}-\alpha\left(C_{M}+C_{E}+C_{T}\right)\right]^{2}}{4\left(4 \alpha k-\beta^{2}\right)^{2}\left(8 \alpha k-\beta^{2}\right)^{2}}>0, \text { so } \prod_{1}^{*}=\prod_{3}^{*}>\prod_{2}^{*} .
\end{aligned}
$$

Proposition 2. Under centralized decision-making, the effort of the express company is higher than that of semicentralized decision-making. That is, $s_{4}^{*}>s_{3}^{*}=s_{1}^{*}>s_{2}^{*}$ and $s_{4}^{*}=2 s_{3}^{*}=2 s_{1}^{*}$. The sales volume of the product under the centralized decision is higher than that in the individual decision. That is, $q_{4}^{*}>q_{3}^{*}=q_{1}^{*}>q_{2}^{*}$ and $q_{4}^{*}=2 q_{3}^{*}=2 q_{1}^{*}$. The selling price of the product under the individual decision is higher than that in the semicentralized decision. That is, $p_{2}^{*}>p_{1}^{*}=p_{3}^{*}>p_{4}^{*}$ :

$$
\begin{aligned}
\left(\frac{s_{4}^{*}}{s_{3}^{*}}\right) & =\frac{\left(\beta\left[Q_{0}-\alpha\left(C_{M}+C_{E}+C_{T}\right)\right] / 4 \alpha k-\beta^{2}\right)}{\left(\beta\left[Q_{0}-\alpha\left(C_{M}+C_{E}+C_{T}\right)\right] / 2\left(4 \alpha k-\beta^{2}\right)\right)}=2, \text { so } s_{4}^{*}>s_{3}^{*} \text { and } s_{4}^{*}=2 s_{3}^{*}, \\
\frac{s_{1}^{*}}{s_{2}^{*}} & =\frac{\left(\beta\left[Q_{0}-\alpha\left(C_{M}+C_{E}+C_{T}\right)\right] / 2\left(4 \alpha k-\beta^{2}\right)\right)}{\left(\beta\left[Q_{0}-\alpha\left(C_{M}+C_{E}+C_{T}\right)\right] / 8 \alpha k-\beta^{2}\right)}=\frac{8 \alpha k-\beta^{2}}{2\left(4 \alpha k-\beta^{2}\right)}>1, \text { so } s_{1}^{*}>s_{2}^{*}, \\
\frac{q_{4}^{*}}{q_{3}^{*}} & =\frac{\left(2 \alpha \mathrm{k}\left[Q_{0}-\alpha\left(C_{M}+C_{E}+C_{T}\right)\right] / 4 \alpha k-\beta^{2}\right)}{\left(\alpha \mathrm{k}\left[Q_{0}-\alpha\left(C_{M}+C_{E}+C_{T}\right)\right] / 4 \alpha k-\beta^{2}\right)}=2, \text { so } q_{4}^{*}>q_{3}^{*}, \text { and } q_{4}^{*}=2 q_{3}^{*}, \\
\frac{q_{1}^{*}}{q_{2}^{*}} & =\frac{\left(\alpha \mathrm{k}\left[Q_{0}-\alpha\left(C_{M}+C_{E}+C_{T}\right)\right] / 4 \alpha k-\beta^{2}\right)}{\left(2 \alpha \mathrm{k}\left[Q_{0}-\alpha\left(C_{M}+C_{E}+C_{T}\right)\right] / 8 \alpha k-\beta^{2}\right)}=\frac{8 \alpha k-\beta^{2}}{2\left(4 \alpha k-\beta^{2}\right)}>1, \text { so } q_{2}^{*}>q_{3}^{*}, \\
\frac{q_{3}^{*}}{q_{1}^{*}} & =\frac{\left(2 \alpha \mathrm{k}\left[Q_{0}-\alpha\left(C_{M}+C_{E}+C_{T}\right)\right] / 8 \alpha k-\beta^{2}\right)}{\left(\alpha \mathrm{k}\left[Q_{0}-\alpha\left(C_{M}+C_{E}+C_{T}\right)\right] / 8 \alpha k-\beta^{2}\right)}=2, \text { so } q_{3}^{*}>q_{1}^{*}, \text { and } q_{1}^{*}>q_{2}^{*}, \\
p_{3}^{*}-p_{1}^{*} & =\frac{\beta^{2}\left(2 \alpha k-\beta^{2}\right)\left[Q_{0}-\alpha\left(C_{M}+C_{E}+C_{T}\right)\right]}{2 \alpha\left(4 \alpha k-\beta^{2}\right)\left(8 \alpha k-\beta^{2}\right)}>0, \text { so } p_{1}^{*}=p_{3}^{*}<p_{2}^{*}, \\
p_{4}^{*} & =\frac{\left(2 \alpha k-\beta^{2}\right)\left[Q_{0}-\alpha\left(C_{M}+C_{E}+C_{T}\right)\right]}{2 \alpha\left(4 k-\text { so } p_{4}^{*}<p_{3}^{*}=p_{1}^{*} .\right.},
\end{aligned}
$$

Proposition 3. Among the three models of semicentralized decision-making, the total profits of semicentralized models 1 and 3 are both superior to that of semicentralized model 2. Furthermore, E-commerce mall can achieve the highest profit in semicentralized model 3 .

It is proved below.

From Propositions 1 and 2, it is obvious that $\prod_{1}^{*}=\prod_{3}^{*}>\prod_{2}^{*}, \quad s_{3}^{*}=s_{1}^{*}>s_{2}^{*}, \quad q_{3}^{*}=q_{1}^{*}>q_{2}^{*}, \quad$ and $p_{2}^{*}>p_{1}^{*}=p_{3}^{*}$, so when E-commerce mall and end-distributor alliance and express company and end-distributor alliance, the overall effect of logistics service supply chain is better than E-commerce mall and express company alliance:

$$
\begin{aligned}
\prod_{M 3}^{*} & =\prod_{E T}^{*}=\frac{k\left[Q_{0}-\alpha\left(C_{M}+C_{E}+C_{T}\right)\right]^{2}}{2\left(4 \alpha k-\beta^{2}\right)} \\
& >\prod_{M 3}^{*} \frac{k\left[Q_{0}-\alpha\left(C_{M}+C_{E}+C_{T}\right)\right]^{2}}{8 \alpha k-\beta^{2}} .
\end{aligned}
$$

That is, when the express company forms an alliance with the terminal distribution service provider, the profit of 
the E-commerce mall $\prod_{M 3}^{*}$ is equal to the overall profit of the E-commerce mall and the terminal distribution service provider alliance $\prod_{E T}^{*}$ and is higher than the overall profit of the E-commerce mall and the express company alliance $\prod_{M E}^{*}$. Therefore, the E-commerce mall can achieve the highest profit in semicentralized model 3.

\section{Contract Coordination Mechanism}

Based on Table 2, the overall profit of LSSC under centralized decision-making is significantly higher than that under semicentralized decision-making models. Therefore, to achieve the performance of centralized decision-making under semicentralized scenarios, supply chain coordination strategies are introduced to improve the overall profit and achieve the win-win situation.

This section firstly discusses the profit range of each partner for the three semicentralized alliances. Secondly, it introduces the specific coordination schemes. Since the alliance of semicentralized model 3 is equivalent to a twoechelon LSSC composed of the E-commerce mall and the logistics service provider, this study mainly focuses on the coordination of semicentralized models 1 and 2 . Then, the contract coordination scheme for semicentralized model 1 are discussed in the two cases: (1) $3 \beta^{2}-4 \alpha k>0$ and (2) $3 \beta^{2}-4 \alpha k<0$. Finally, this work investigates the contract coordination scheme semicentralized model 2 .

\subsection{Profit Range of Three Semicentralized Models}

\subsubsection{Profit Range of Semicentralized Model 1}

Proposition 4. Under the supply chain coordination, the profit ranges of the alliance formed by the E-commerce mall and the terminal distribution service provider and the express company are obtained below, respectively:

$$
\begin{gathered}
\frac{k\left[Q_{0}-\alpha\left(C_{M}+C_{E}+C_{T}\right)\right]^{2}}{2\left(4 \alpha k-\beta^{2}\right)} \leq \prod_{M T} \leq \frac{3 k\left[Q_{0}-\alpha\left(C_{M}+C_{E}+C_{T}\right)\right]^{2}}{4\left(4 \alpha k-\beta^{2}\right)}, \\
\frac{k\left[Q_{0}-\alpha\left(C_{M}+C_{E}+C_{T}\right)\right]^{2}}{4\left(4 \alpha k-\beta^{2}\right)} \leq \prod_{E} \leq \frac{k\left[Q_{0}-\alpha\left(C_{M}+C_{E}+C_{T}\right)\right]^{2}}{2\left(4 \alpha k-\beta^{2}\right)} .
\end{gathered}
$$

It is proved as follows.

se purpose of the contract coordination between the alliance including the E-commerce mall, the terminal distribution service provider, and the express company is to achieve the performance of centralized decisionmaking and all-win status. \&at is, the profits of all parties are not lower than the profit before the coordination since

$$
\begin{array}{r}
\prod_{M T}+\prod_{E}=\frac{k\left[Q_{0}-\alpha\left(C_{M}+C_{E}+C_{T}\right)\right]^{2}}{4 \alpha k-\beta^{2}}, \\
\prod_{M T} \geq \frac{k\left[Q_{0}-\alpha\left(C_{M}+C_{E}+C_{T}\right)\right]^{2}}{2\left(4 \alpha k-\beta^{2}\right)}, \\
\prod_{E} \geq \frac{k\left[Q_{0}-\alpha\left(C_{M}+C_{E}+C_{T}\right)\right]^{2}}{4\left(4 \alpha k-\beta^{2}\right)} .
\end{array}
$$

Therefore,

$$
\begin{aligned}
& \frac{k\left[Q_{0}-\alpha\left(C_{M}+C_{E}+C_{T}\right)\right]^{2}}{2\left(4 \alpha k-\beta^{2}\right)} \leq \prod_{M T} \leq \frac{3 k\left[Q_{0}-\alpha\left(C_{M}+C_{E}+C_{T}\right)\right]^{2}}{4\left(4 \alpha k-\beta^{2}\right)}, \\
& \frac{k\left[Q_{0}-\alpha\left(C_{M}+C_{E}+C_{T}\right)\right]^{2}}{4\left(4 \alpha k-\beta^{2}\right)} \leq \prod_{E} \leq \frac{k\left[Q_{0}-\alpha\left(C_{M}+C_{E}+C_{T}\right)\right]^{2}}{2\left(4 \alpha k-\beta^{2}\right)} .
\end{aligned}
$$

\subsubsection{Profit Range of Semicentralized Model 2}

Proposition 5. Under the supply chain coordination, the profit ranges of the alliance including the E-commerce mall and the express company and the terminal distribution service provider are below:

$$
\begin{aligned}
\frac{k\left[Q_{0}-\alpha\left(C_{M}+C_{E}+C_{T}\right)\right]^{2}}{8 \alpha k-\beta^{2}} \leq \prod_{M E} \leq \frac{k\left(48 \alpha^{2} k^{2}-12 \alpha k \beta^{2}+\beta^{4}\right)\left[Q_{0}-\alpha\left(C_{M}+C_{E}+C_{T}\right)\right]^{2}}{\left(8 \alpha k-\beta^{2}\right)^{2}\left(4 \alpha k-\beta^{2}\right)}, \\
\frac{4 \alpha k^{2}\left[Q_{0}-\alpha\left(C_{M}+C_{E}+C_{T}\right)\right]^{2}}{\left(8 \alpha k-\beta^{2}\right)^{2}} \leq \prod_{T} \leq \frac{4 \alpha k^{2}\left[Q_{0}-\alpha\left(C_{M}+C_{E}+C_{T}\right)\right]^{2}}{\left(8 \alpha k-\beta^{2}\right)\left(4 \alpha k-\beta^{2}\right)} .
\end{aligned}
$$

It is proved as follows.

se purpose of the contract coordination between the alliance composed of the E-commerce mall and the express company and the terminal distribution service provider is to make the profits of the two parties after the coordination reach the effect of centralized decision-making, and the profits of the parties are not lower than the profits before the coordination. Hence, 


$$
\begin{aligned}
& \prod_{M E}+\prod_{T}=\frac{k\left[Q_{0}-\alpha\left(C_{M}+C_{E}+C_{T}\right)\right]^{2}}{4 \alpha k-\beta^{2}}, \\
& \prod_{M E} \geq \frac{k\left[Q_{0}-\alpha\left(C_{M}+C_{E}+C_{T}\right)\right]^{2}}{8 \alpha k-\beta^{2}}, \\
& \prod_{T} \geq \frac{4 \alpha k^{2}\left[Q_{0}-\alpha\left(C_{M}+C_{E}+C_{T}\right)\right]^{2}}{\left(8 \alpha k-\beta^{2}\right)^{2}} .
\end{aligned}
$$$$
\text { Therefore, }
$$

$$
\begin{gathered}
\frac{k\left[Q_{0}-\alpha\left(C_{M}+C_{E}+C_{T}\right)\right]^{2}}{8 \alpha k-\beta^{2}} \leq \prod_{M E} \leq \frac{k\left(48 \alpha^{2} k^{2}-12 \alpha k \beta^{2}+\beta^{4}\right)\left[Q_{0}-\alpha\left(C_{M}+C_{E}+C_{T}\right)\right]^{2}}{\left(8 \alpha k-\beta^{2}\right)^{2}\left(4 \alpha k-\beta^{2}\right)}, \\
\frac{4 \alpha k^{2}\left[Q_{0}-\alpha\left(C_{M}+C_{E}+C_{T}\right)\right]^{2}}{\left(8 \alpha k-\beta^{2}\right)^{2}} \leq \prod_{T} \leq \frac{4 \alpha k^{2}\left[Q_{0}-\alpha\left(C_{M}+C_{E}+C_{T}\right)\right]^{2}}{\left(8 \alpha k-\beta^{2}\right)\left(4 \alpha k-\beta^{2}\right)} .
\end{gathered}
$$

\subsubsection{Profit Range of Semicentralized Model 3}

Proposition 6. Under the contract coordination mechanism, the profit range of the express company and the terminal distribution service provider alliance and the E-commerce mall are derived as follows, respectively:

$$
\begin{aligned}
& \frac{k\left[Q_{0}-\alpha\left(C_{M}+C_{E}+C_{T}\right)\right]^{2}}{2\left(4 \alpha k-\beta^{2}\right)} \leq \prod_{M} \leq \frac{3 k\left[Q_{0}-\alpha\left(C_{M}+C_{E}+C_{T}\right)\right]^{2}}{4\left(4 \alpha k-\beta^{2}\right)}, \\
& \frac{k\left[Q_{0}-\alpha\left(C_{M}+C_{E}+C_{T}\right)\right]^{2}}{4\left(4 \alpha k-\beta^{2}\right)} \leq \prod_{E T} \leq \frac{k\left[Q_{0}-\alpha\left(C_{M}+C_{E}+C_{T}\right)\right]^{2}}{2\left(4 \alpha k-\beta^{2}\right)} .
\end{aligned}
$$

It is proved below.

The purpose of the contract coordination between the alliance composed of the express company and the terminal distribution service provider and the E-commerce mall is to make the profits of the two parties after the coordination reach the effect of centralized decision-making, and the profits of the parties are not lower than the profits before the coordination. Hence,

$$
\begin{array}{r}
\prod_{M}+\prod_{E T}=\frac{k\left[Q_{0}-\alpha\left(C_{M}+C_{E}+C_{T}\right)\right]^{2}}{4 \alpha k-\beta^{2}}, \\
\prod_{M} \geq \frac{k\left[Q_{0}-\alpha\left(C_{M}+C_{E}+C_{T}\right)\right]^{2}}{2\left(4 \alpha k-\beta^{2}\right)}, \\
\prod_{E T} \geq \frac{k\left[Q_{0}-\alpha\left(C_{M}+C_{E}+C_{T}\right)\right]^{2}}{4\left(4 \alpha k-\beta^{2}\right)} .
\end{array}
$$

Therefore,

$$
\begin{gathered}
\frac{k\left[Q_{0}-\alpha\left(C_{M}+C_{E}+C_{T}\right)\right]^{2}}{2\left(4 \alpha k-\beta^{2}\right)} \leq \prod_{M} \leq \frac{3 k\left[Q_{0}-\alpha\left(C_{M}+C_{E}+C_{T}\right)\right]^{2}}{4\left(4 \alpha k-\beta^{2}\right)}, \\
\frac{k\left[Q_{0}-\alpha\left(C_{M}+C_{E}+C_{T}\right)\right]^{2}}{4\left(4 \alpha k-\beta^{2}\right)} \leq \prod_{E T} \leq \frac{k\left[Q_{0}-\alpha\left(C_{M}+C_{E}+C_{T}\right)\right]^{2}}{2\left(4 \alpha k-\beta^{2}\right)} .
\end{gathered}
$$

\subsection{Coordination Strategy of Semicentralized Model 1}

Proposition 7. When $3 \beta^{2}-4 \alpha k>0$, the alliance needs to transfer some profit to the express company, and when $3 \beta^{2}-4 \alpha k<0$, it suggests that one partner should share some profit with the other.

It is proved as follows.

When

$$
\begin{aligned}
s_{4}^{*} & =\frac{\beta\left[Q_{0}-\alpha\left(C_{M}+C_{E}+C_{T}\right)\right]}{4 \alpha k-\beta^{2}}, \\
p_{4}^{*} & =\frac{2 k Q_{0}+\left(2 \alpha k-\beta^{2}\right)\left(C_{M}+C_{E}+C_{T}\right)}{4 \alpha k-\beta^{2}}, \\
W_{E} & =\frac{k\left[Q_{0}-\alpha\left(C_{M}+C_{T}\right)\right]+\left(3 \alpha k-\beta^{2}\right) C_{E}}{4 \alpha k-\beta^{2}},
\end{aligned}
$$

then

$$
\begin{aligned}
& \prod_{M T}=\frac{2 \alpha k^{2}\left[Q_{0}-\alpha\left(C_{M}+C_{E}+C_{T}\right)\right]^{2}}{\left(4 \alpha k-\beta^{2}\right)^{2}} \\
& \prod_{E}=\frac{k\left(2 \alpha k-\beta^{2}\right)\left[Q_{0}-\alpha\left(C_{M}+C_{E}+C_{T}\right)\right]^{2}}{\left(4 \alpha k-\beta^{2}\right)^{2}} .
\end{aligned}
$$




$$
\begin{aligned}
& \frac{k\left[Q_{0}-\alpha\left(C_{M}+C_{E}+C_{T}\right)\right]^{2}}{2\left(4 \alpha k-\beta^{2}\right)} \leq \prod_{M T} \leq \frac{3 k\left[Q_{0}-\alpha\left(C_{M}+C_{E}+C_{T}\right)\right]^{2}}{4\left(4 \alpha k-\beta^{2}\right)}, \\
& \frac{k\left[Q_{0}-\alpha\left(C_{M}+C_{E}+C_{T}\right)\right]^{2}}{4\left(4 \alpha k-\beta^{2}\right)} \leq \prod_{E} \leq \frac{k\left[Q_{0}-\alpha\left(C_{M}+C_{E}+C_{T}\right)\right]^{2}}{2\left(4 \alpha k-\beta^{2}\right)} .
\end{aligned}
$$

When $3 \beta^{2}-4 \alpha k>0, \prod_{M T}>\prod_{M T \max }=\left(3 k\left[Q_{0}-\alpha\left(C_{M}+\right.\right.\right.$ $\left.\left.\left.C_{E}+C_{T}\right)\right]^{2} / 4\left(4 \alpha k-\beta^{2}\right)\right)$, and the alliance needs to transfer some profit to the express company. When $3 \beta^{2}-4 \alpha k<0$, $\prod_{M T}<\prod_{M T \max }=\left(3 k \quad\left[Q_{0}-\alpha\left(C_{M}+C_{E}+C_{T}\right)\right]^{2} / 4(4 \alpha k-\right.$ $\left.\beta^{2}\right)$ ), and one partner should share some profit with the other.

Based on this, there are two situations in the contract coordination scheme. When $3 \beta^{2}-4 \alpha k>0$, the contract coordination scheme is (1) the strategy of transferring part of the profit to the express company by the alliance including E-commerce mall and the terminal distribution service provider, (2) the strategy of the alliance bearing part of the logistics service cost for the express companies, and (3) the strategy of increasing unit delivery price of the express company. When $3 \beta^{2}-4 \alpha k<0$, the contract coordination scheme is (1) the strategy of transferring some revenue to the express company from the alliance of E-commerce mall and the terminal distribution service provider, (2) the strategy of the alliance undertaking part of the logistics service cost, (3) the strategy of raising the unit delivery price of express company logistics services, and (4) the strategy of transferring some revenue to the express company from the alliance of E-commerce mall and the terminal distribution service provider.

5.2.1. Case 1: $3 \beta^{2}-4 \alpha k>0$. As mentioned above, there are three kinds of contract coordination schemes when $3 \beta^{2}-4 \alpha k>0$, (1) the alliance transfers part of the profit to the express company, (2) the alliance bears some logistics service cost of the express company, and (3) the alliance increases the unit delivery price of the express company.

A1: Revenue Sharing Coordination in Semicentralized Model 1.

Proposition 8. In order to achieve the centralized decisionmaking selling price $p$ and the effort level of logistics service $s$ and the unit delivery price, $W_{B}$ remains unchanged, assuming that the revenue sharing ratio of the alliance composed of the E-commerce mall and the terminal distribution service provider to the express company is $\theta_{1}$; when $\left(\left(3 \beta^{2}-4 \alpha k\right)\left[Q_{0}-\right.\right.$ $\left.\alpha\left(C_{M}+C_{E}+C_{T}\right)\right] / 8 \alpha \quad\left[2 k Q_{0}+\left(2 \alpha k-\beta^{2}\right) \quad\left(C_{M}+C_{E}+\right.\right.$ $\left.\left.\left.C_{T}\right)\right]\right) \leq \theta_{1} \leq\left(\beta^{2}\left[Q_{0}-\alpha\left(C_{M}+C_{E}+C_{T}\right)\right] / 4 \alpha\left[2 k Q_{0}+(2 \alpha k-\right.\right.$ $\left.\left.\left.\beta^{2}\right)\left(C_{M}+C_{E}+C_{T}\right)\right]\right)$, the profit coordination between the alliance and express company can be realized.

It is proved as follows.

Assuming the revenue sharing ratio of the alliance to the express company is $\theta_{1}$ and $0<\theta_{1}<1$, then the profit of the alliance is $\prod_{M T}=\left[\left(1-\theta_{1}\right) p-C_{M}-C_{T}-W_{E}\right] q$ and the profit of the express company is $\prod_{E}=\left(W_{E}+\theta_{1} p-C_{E}\right)$ $q-k s^{2}$.

When

$$
\begin{aligned}
p & =\frac{2 k Q_{0}+\left(2 \alpha k-\beta^{2}\right)\left(C_{M}+C_{E}+C_{T}\right)}{4 \alpha k-\beta^{2}}, \\
s & =\frac{\beta\left[Q_{0}-\alpha\left(C_{M}+C_{E}+C_{T}\right)\right]}{4 \alpha k-\beta^{2}}, \\
W_{E} & =\frac{k\left[Q_{0}-\alpha\left(C_{M}+C_{T}\right)\right]+\left(3 \alpha k-\beta^{2}\right) C_{E}}{4 \alpha k-\beta^{2}},
\end{aligned}
$$

then

$$
\begin{aligned}
\prod_{M T}= & \frac{2 \alpha k\left[Q_{0}-\alpha\left(C_{M}+C_{E}+C_{T}\right)\right]}{\left(4 \alpha k-\beta^{2}\right)^{2}}\left\{\left(1-2 \theta_{1}\right) k Q_{0}\right. \\
& \left.-\left[\left(1+2 \theta_{1}\right) \alpha k-\theta_{1} \beta^{2}\right]\left(C_{M}+C_{E}+C_{T}\right)\right\}, \\
\prod_{E}= & \frac{k\left[Q_{0}-\alpha\left(C_{M}+C_{E}+C_{T}\right)\right]}{\left(4 \alpha k-\beta^{2}\right)^{2}}\left\{\left[\left(1+2 \theta_{1}\right) 2 \alpha k-\beta^{2}\right] Q_{0}\right. \\
& \left.-\alpha\left(1-2 \theta_{1}\right)\left(2 \alpha k-\beta^{2}\right)\left(C_{M}+C_{E}+C_{T}\right)\right\} .
\end{aligned}
$$

Since

$$
\begin{aligned}
& \frac{k\left[Q_{0}-\alpha\left(C_{M}+C_{E}+C_{T}\right)\right]^{2}}{2\left(4 \alpha k-\beta^{2}\right)} \leq \prod_{M T} \leq \frac{3 k\left[Q_{0}-\alpha\left(C_{M}+C_{E}+C_{T}\right)\right]^{2}}{4\left(4 \alpha k-\beta^{2}\right)}, \\
& \frac{k\left[Q_{0}-\alpha\left(C_{M}+C_{E}+C_{T}\right)\right]^{2}}{4\left(4 \alpha k-\beta^{2}\right)} \leq \prod_{E} \leq \frac{k\left[Q_{0}-\alpha\left(C_{M}+C_{E}+C_{T}\right)\right]^{2}}{2\left(4 \alpha k-\beta^{2}\right)},
\end{aligned}
$$

then

$$
\begin{aligned}
& \frac{\left(3 \beta^{2}-4 \alpha k\right)\left[Q_{0}-\alpha\left(C_{M}+C_{E}+C_{T}\right)\right]}{8 \alpha\left[2 k Q_{0}+\left(2 \alpha k-\beta^{2}\right)\left(C_{M}+C_{E}+C_{T}\right)\right]} \leq \theta_{1} \\
& \leq \frac{\beta^{2}\left[Q_{0}-\alpha\left(C_{M}+C_{E}+C_{T}\right)\right]}{4 \alpha\left[2 k Q_{0}+\left(2 \alpha k-\beta^{2}\right)\left(C_{M}+C_{E}+C_{T}\right)\right]} .
\end{aligned}
$$

B1: Cost Sharing Coordination in Semicentralized Model 1.

Proposition 9. In order to achieve the centralized decisionmaking of sales price $p$ and the logistics service s and keep the unit delivery price $W_{E}$ unchanged, assuming that the cost sharing proportion of $s$ by the alliance is $\eta_{1}, 0<\eta_{1}<1$, then when $\left(3 \beta^{2}-4 \alpha k / 4 \beta^{2}\right) \leq \eta_{1} \leq(1 / 2)$, the alliance and the express company can achieve the profit coordination.

It is proved in the following.

Assuming that the cost sharing ratio of logistics service cost is $\eta_{1}$ and $0<\eta_{1}<1$, the profit of the alliance is $\prod_{M T}=$ $\left(p-C_{M}-C_{T}-W_{E}\right) q-\eta_{1} k s^{2}$ and the profit of the express company is $\prod_{E}=\left(W_{E}+\theta_{1} p-C_{E}\right) q-k s^{2}$.

When 


$$
\begin{aligned}
p & =\frac{2 k Q_{0}+\left(2 \alpha k-\beta^{2}\right)\left(C_{M}+C_{E}+C_{T}\right)}{4 \alpha k-\beta^{2}}, \\
s & =\frac{\beta\left[Q_{0}-\alpha\left(C_{M}+C_{E}+C_{T}\right)\right]}{4 \alpha k-\beta^{2}}, \\
W_{E} & =\frac{k\left[Q_{0}-\alpha\left(C_{M}+C_{T}\right)\right]+\left(3 \alpha k-\beta^{2}\right) C_{E}}{4 \alpha k-\beta^{2}},
\end{aligned}
$$

then

$$
\begin{aligned}
& \prod_{M T}=\frac{k\left(2 \alpha k-\eta_{1} \beta^{2}\right)\left[Q_{0}-\alpha\left(C_{M}+C_{E}+C_{T}\right)\right]^{2}}{\left(4 \alpha k-\beta^{2}\right)^{2}}, \\
& \prod_{E}=\frac{k\left[2 \alpha k-\left(1-\eta_{1}\right) \beta^{2}\right]\left[Q_{0}-\alpha\left(C_{M}+C_{E}+C_{T}\right)\right]^{2}}{\left(4 \alpha k-\beta^{2}\right)^{2}} .
\end{aligned}
$$

Since

$$
\begin{aligned}
& \frac{k\left[Q_{0}-\alpha\left(C_{M}+C_{E}+C_{T}\right)\right]^{2}}{2\left(4 \alpha k-\beta^{2}\right)} \leq \prod_{M T} \leq \frac{3 k\left[Q_{0}-\alpha\left(C_{M}+C_{E}+C_{T}\right)\right]^{2}}{4\left(4 \alpha k-\beta^{2}\right)}, \\
& \frac{k\left[Q_{0}-\alpha\left(C_{M}+C_{E}+C_{T}\right)\right]^{2}}{4\left(4 \alpha k-\beta^{2}\right)} \leq \prod_{E} \leq \frac{k\left[Q_{0}-\alpha\left(C_{M}+C_{E}+C_{T}\right)\right]^{2}}{2\left(4 \alpha k-\beta^{2}\right)},
\end{aligned}
$$

then

$$
\frac{3 \beta^{2}-4 \alpha k}{4 \beta^{2}} \leq \eta_{1} \leq \frac{1}{2} .
$$

C1: Coordination of Unit Delivery Price in Semicentralized Model 1.

Proposition 10. In order to achieve the centralized decisionmaking selling price $p$ and the effort level of express service s, the unit price of express service $W_{B}$ remains unchanged; if the alliance increases the unit delivery price by $\varphi_{1}, 0<\varphi_{1}<1$, when $\left(\left(3 \beta^{2}-4 \alpha k\right)\left[Q_{0}-\alpha\left(C_{M}+C_{E}+C_{T}\right)\right] / 8 \alpha\left\{k\left[Q_{0}-\alpha\right.\right.\right.$ $\left.\left.\left.\left(C_{M}+C_{T}\right)\right]+\left(3 \alpha k-\beta^{2}\right) C_{E}\right\}\right) \leq \varphi_{1} \leq\left(\beta^{2}\left[Q_{0}-\alpha\left(C_{M}+C_{E}+\right.\right.\right.$ $\left.\left.\left.C_{T}\right)\right] / 4 \alpha\left\{k\left[Q_{0}-\alpha\left(C_{M}+C_{T}\right)\right]+\left(3 \alpha k-\beta^{2}\right) C_{E}\right\}\right)\left(3 \beta^{2}-4 \alpha k\right.$ $>0)$, then the alliance and the express company can achieve profit coordination.

It is proved as follows.

Assume that the rate of increase in express unit price is $\varphi$ and $0<\varphi<1$, then the profit of the alliance is $\prod_{M T}=\left[p-C_{M}-C_{T}-\left(1+\varphi_{1}\right) W_{E}\right] q$, and the profit of the express company is $\prod_{E}=\left[\left(1+\varphi_{1}\right) W_{E}-C_{E}\right] q-k s^{2}$.

When

$$
\begin{aligned}
p & =\frac{2 k Q_{0}+\left(2 \alpha k-\beta^{2}\right)\left(C_{M}+C_{E}+C_{T}\right)}{4 \alpha k-\beta^{2}}, \\
s & =\frac{\beta\left[Q_{0}-\alpha\left(C_{M}+C_{E}+C_{T}\right)\right]}{4 \alpha k-\beta^{2}}, \\
W_{E} & =\frac{k\left[Q_{0}-\alpha\left(C_{M}+C_{T}\right)\right]+\left(3 \alpha k-\beta^{2}\right) C_{E}}{4 \alpha k-\beta^{2}},
\end{aligned}
$$

then

$$
\begin{aligned}
\prod_{M T}= & \frac{2 \alpha \mathrm{k}\left[Q_{0}-\alpha\left(C_{M}+C_{E}+C_{T}\right)\right]}{\left(4 \alpha k-\beta^{2}\right)^{2}}\left\{\left(1-\varphi_{1}\right) k\right. \\
& \left.\cdot\left[Q_{0}-\alpha\left(C_{M}+C_{T}\right)\right]-\left[\left(1+3 \varphi_{1}\right) \alpha k-\varphi_{1} \beta^{2}\right] C_{E}\right\}, \\
\prod_{E}= & \frac{\mathrm{k}\left[Q_{0}-\alpha\left(C_{M}+C_{E}+C_{T}\right)\right]}{\left(4 \alpha k-\beta^{2}\right)^{2}}\left\{\left[\left(1+\varphi_{1}\right) 2 \alpha k-\beta^{2}\right]\right. \\
& \left.\cdot\left[Q_{0}-\alpha\left(C_{M}+C_{T}\right)\right]+\alpha\left[\left(3 \varphi_{1}-1\right) 2 \alpha k+\left(1-2 \varphi_{1}\right) \beta^{2}\right] C_{E}\right\} .
\end{aligned}
$$

Since

$$
\begin{aligned}
& \frac{k\left[Q_{0}-\alpha\left(C_{M}+C_{E}+C_{T}\right)\right]^{2}}{2\left(4 \alpha k-\beta^{2}\right)} \leq \prod_{M T} \leq \frac{3 k\left[Q_{0}-\alpha\left(C_{M}+C_{E}+C_{T}\right)\right]^{2}}{4\left(4 \alpha k-\beta^{2}\right)}, \\
& \frac{k\left[Q_{0}-\alpha\left(C_{M}+C_{E}+C_{T}\right)\right]^{2}}{4\left(4 \alpha k-\beta^{2}\right)} \leq \prod_{E} \leq \frac{k\left[Q_{0}-\alpha\left(C_{M}+C_{E}+C_{T}\right)\right]^{2}}{2\left(4 \alpha k-\beta^{2}\right)},
\end{aligned}
$$

then

$$
\begin{aligned}
& \frac{\left(3 \beta^{2}-4 \alpha k\right)\left[Q_{0}-\alpha\left(C_{M}+C_{E}+C_{T}\right)\right]}{8 \alpha\left\{k\left[Q_{0}-\alpha\left(C_{M}+C_{T}\right)\right]+\left(3 \alpha k-\beta^{2}\right) C_{E}\right\}} \leq \varphi_{1} \\
& \leq \frac{\beta^{2}\left[Q_{0}-\alpha\left(C_{M}+C_{E}+C_{T}\right)\right]}{4 \alpha\left\{k\left[Q_{0}-\alpha\left(C_{M}+C_{T}\right)\right]+\left(3 \alpha k-\beta^{2}\right) C_{E}\right\}} .
\end{aligned}
$$

5.2.2. Case 2: $3 \beta^{2}-4 \alpha k<0$. As mentioned above, when $3 \beta^{2}-4 \alpha k<0$, there are four coordination schemes: (1) the alliance transfers part of the revenue to the express company; (2) the alliance bears some of the logistics service effort cost for the express companies; (3) the alliance increases the unit delivery price of the express company; and (4) the express company transfers some of the revenue to the alliance.

A2: Revenue Sharing Coordination in Semicentralized Model 1

Proposition 11. In order to achieve the centralized decisionmaking sales price $p$ and the effort level of logistics services, the service unit price of the express deliver $W_{B}$ remains unchanged, assuming that the revenue sharing ratio of the alliance composed of the E-commerce mall and the terminal distribution service provider to the express company is $\theta_{2}$, $0<\theta_{2}<1$; when $0<\theta_{2} \leq\left(\beta^{2}\left[Q_{0}-\alpha\left(C_{M}+C_{E}+C_{T}\right)\right] /\right.$ $\left.4 \alpha\left[2 k Q_{0}+\left(2 \alpha k-\beta^{2}\right)\left(C_{M}+C_{E}+C_{T}\right)\right]\right)$, the profit coordination between the alliance and express company can be realized.

With the similar proof in Proposition 7, we can obtain that

$$
0<\theta_{2} \leq \frac{\beta^{2}\left[Q_{0}-\alpha\left(C_{M}+C_{E}+C_{T}\right)\right]}{4 \alpha\left[2 k Q_{0}+\left(2 \alpha k-\beta^{2}\right)\left(C_{M}+C_{E}+C_{T}\right)\right]} .
$$

B2: Cost Sharing Coordination in Semicentralized Model 1 
Proposition 12. In order to achieve the centralized decisionmaking of sales price $p$ and effort level of express service s, keep the unit price of the express service $W_{E}$ unchanged, assuming that the sharing proportion of the logistics service effort cost is $\eta_{2}, 0<\eta_{2}<1$, then when $0<\eta_{2} \leq(1 / 2)$, the alliance and the express company can achieve profit coordination.

With the similar proof in Proposition 8, we have

$$
0<\eta_{2} \leq \frac{1}{2}
$$

C2: Coordination of Unit Delivery Price of Logistics Service in Semicentralized Model 1

Proposition 13. In order to achieve the centralized decisionmaking sales price $p$ and the effort level of express services, the unit price of express service $W_{B}$ remains unchanged; if the alliance increases the unit delivery price by $\varphi_{2}, 0<\varphi_{2}<1$, when $0<\varphi_{2} \leq\left(\beta^{2}\left[Q_{0}-\alpha\left(C_{M}+C_{E}+C_{T}\right)\right] / 4 \alpha\left\{k\left[Q_{0}-\alpha\left(C_{M^{+}}\right.\right.\right.\right.$ $\left.\left.\left.\left.C_{T}\right)\right]+\left(3 \alpha k-\beta^{2}\right) C_{E}\right\}\right)$, then the alliance and the express company can achieve profit coordination.

With the similar proof in Proposition 8, we have

$$
0<\varphi_{2} \leq \frac{\beta^{2}\left[Q_{0}-\alpha\left(C_{M}+C_{E}+C_{T}\right)\right]}{4 \alpha\left\{k\left[Q_{0}-\alpha\left(C_{M}+C_{T}\right)\right]+\left(3 \alpha k-\beta^{2}\right) C_{E}\right\}}
$$

D2: Coordination Strategy of Transferring Part of the Express Company's Profit to the Alliance

Proposition 14. In order to achieve the centralized decisionmaking of sales price $p$ and the effort level of logistics services, the service unit price of the express service provider $W_{E}$ remains unchanged, assuming that the revenue sharing ratio of the express company is $\delta, 0<\delta<1$, then when $0<\delta \leq((4 \alpha k-$ $\left.3 \beta^{2}\right)\left[Q_{0}-\alpha\left(C_{M}+C_{E}+C_{T}\right)\right] / \quad 8 \alpha\left\{k\left[Q_{0}-\alpha\left(C_{M}+C_{T}\right)\right]+\right.$ $\left.\left.\left(3 \alpha k-\beta^{2}\right) C_{E}\right\}\right)$, the alliance and the express company can achieve profit coordination.

It is proved as follows.

Assume that the revenue sharing ratio of the express company is $\delta$, and $0<\delta<1$, then the profit of the alliance is $\prod_{M T}=\left[p-C_{M}-C_{T}-(1-\delta) W_{E}\right] q-k s^{2}$, and the profit of the express company is $\prod_{E}=\left[(1-\delta) W_{E}-C_{E}\right] q$.

When

$$
\begin{gathered}
p=\frac{2 k Q_{0}+\left(2 \alpha k-\beta^{2}\right)\left(C_{M}+C_{E}+C_{T}\right)}{4 \alpha k-\beta^{2}}, \\
s=\frac{\beta\left[Q_{0}-\alpha\left(C_{M}+C_{E}+C_{T}\right)\right]}{4 \alpha k-\beta^{2}}, \\
W_{E}=\frac{k\left[Q_{0}-\alpha\left(C_{M}+C_{T}\right)\right]+\left(3 \alpha k-\beta^{2}\right) C_{E}}{4 \alpha k-\beta^{2}},
\end{gathered}
$$

then

$$
\begin{aligned}
\prod_{M T}= & \frac{2 \alpha k\left[Q_{0}-\alpha\left(C_{M}+C_{E}+C_{T}\right)\right]}{\left(4 \alpha k-\beta^{2}\right)^{2}}\{(1+\delta) k \\
& \left.\cdot\left[Q_{0}-a\left(C_{M}+C_{T}\right)\right]+\left[(3 \delta-1) \alpha k-\delta \beta^{2}\right] C_{E}\right\}, \\
\prod_{E}= & \frac{k\left[Q_{0}-\alpha\left(C_{M}+C_{E}+C_{T}\right)\right]}{\left(4 \alpha k-\beta^{2}\right)^{2}}\left\{\left[(1-\delta) 2 \alpha k-\beta^{2}\right]\right. \\
& \left.\cdot\left[Q_{0}-\alpha\left(C_{M}+C_{T}\right)\right]-\alpha\left[(1+3 \delta) 2 \alpha k-(1+2 \delta) \beta^{2}\right] C_{E}\right\} .
\end{aligned}
$$

Since

$$
\begin{aligned}
& \frac{k\left[Q_{0}-\alpha\left(C_{M}+C_{E}+C_{T}\right)\right]^{2}}{2\left(4 \alpha k-\beta^{2}\right)} \leq \prod_{M T} \leq \frac{3 k\left[Q_{0}-\alpha\left(C_{M}+C_{E}+C_{T}\right)\right]^{2}}{4\left(4 \alpha k-\beta^{2}\right)}, \\
& \frac{k\left[Q_{0}-\alpha\left(C_{M}+C_{E}+C_{T}\right)\right]^{2}}{4\left(4 \alpha k-\beta^{2}\right)} \leq \prod_{E} \leq \frac{k\left[Q_{0}-\alpha\left(C_{M}+C_{E}+C_{T}\right)\right]^{2}}{2\left(4 \alpha k-\beta^{2}\right)},
\end{aligned}
$$

hence

$$
0<\delta \leq \frac{\left(4 \alpha k-3 \beta^{2}\right)\left[Q_{0}-\alpha\left(C_{M}+C_{E}+C_{T}\right)\right]}{8 \alpha\left\{k\left[Q_{0}-\alpha\left(C_{M}+C_{T}\right)\right]+\left(3 \alpha k-\beta^{2}\right) C_{E}\right\}} .
$$

5.2.3. Summary. It can be seen from the above analysis that there are two situations in the contract coordination scheme. When $3 \beta^{2}-4 \alpha k>0$, this study proposes three supply chain coordination schemes: (1) the strategy of sharing revenue by the alliance with the express company, (2) the strategy of bearing some of the express company's logistics cost by the alliance, and (3) the strategy of raising the unit delivery price of the express company. When $3 \beta^{2}-4 \alpha k<0$, it develops the four coordination schemes: (1) the strategy of transferring some revenue of the alliance to the express company, (2) the strategy of bearing part of the logistics service effort cost by the alliance, (3) the strategy of increasing the unit delivery price of the express company, and (4) the strategy of transferring part of the express company's profit to the alliance.

\subsection{Coordination Strategy of Semicentralized Model 2}

Proposition 15. Assuming that the E-commerce mall and the express company alliance and the terminal distribution service provider realize the centralized decision-making sales volume through revenue sharing contract, when the unit price of the terminal distribution service provider remains unchanged, the profits of the terminal distribution service provider will increase.

It is proved as follows.

When 


$$
\begin{aligned}
q & =\frac{2 \alpha \mathrm{k}\left[Q_{0}-\alpha\left(C_{M}+C_{E}+C_{T}\right)\right]}{4 \alpha k-\beta^{2}}, \\
W_{T} & =\frac{2 k\left[Q_{0}-\alpha\left(C_{M}+C_{E}\right)\right]+\left(6 \alpha k-\beta^{2}\right) C_{T}}{8 \alpha k-\beta^{2}},
\end{aligned}
$$

then

$$
\begin{aligned}
\prod_{T}= & \left(W_{T}-C_{T}\right) q=\frac{4 \alpha k^{2}\left[Q_{0}-\alpha\left(C_{M}+C_{E}+C_{T}\right)\right]^{2}}{\left(4 \alpha k-\beta^{2}\right)\left(8 \alpha k-\beta^{2}\right)} \\
= & \prod_{T \max }>\prod_{E 2}^{*}=\frac{4 \alpha k^{2}\left[Q_{0}-\alpha\left(C_{M}+C_{E}+C_{T}\right)\right]^{2}}{\left(8 \alpha k-\beta^{2}\right)^{2}} \\
& \frac{4 \alpha k^{2}\left[Q_{0}-\alpha\left(C_{M}+C_{E}+C_{T}\right)\right]^{2}}{\left(8 \alpha k-\beta^{2}\right)^{2}} \leq \prod_{T} \\
\leq & \frac{4 \alpha k^{2}\left[Q_{0}-\alpha\left(C_{M}+C_{E}+C_{T}\right)\right]^{2}}{\left(8 \alpha k-\beta^{2}\right)\left(4 \alpha k-\beta^{2}\right)} .
\end{aligned}
$$

It can be seen that, in the coordination scheme between the alliance and the terminal distribution service provider, only the terminal distribution service provider can share revenue or undertake some cost with the alliance. Hence, there are two coordination schemes: (1) the strategy of sharing revenue of the terminal distribution service provider with the alliance and (2) the strategy of bearing some logistics service effort cost of the alliance by the terminal distribution service provider.

5.3.1. Revenue Sharing Coordination of Semicentralized Model 2
Proposition 16. In order to achieve the centralized decisionmaking of sales price $p$ and the effort level of logistics service s, the service unit price of the terminal distribution service provider $W_{C}$ remains unchanged, assuming that the proportion of sharing the revenue of the terminal distribution service provider is $\theta_{3}, \quad 0<\theta_{3}<1$, then when $0<\theta_{3} \leq\left(8 \alpha k^{2}\left[Q_{0}-\alpha\left(C_{M}+C_{E}+C_{T}\right)\right] /\left(8 \alpha k-\beta^{2}\right)\left\{2 k\left[Q_{0}-\right.\right.\right.$ $\left.\left.\left.\alpha\left(C_{M}+C_{E}\right)\right]+\left(6 \alpha k-\beta^{2}\right) C_{T}\right\}\right)$, the alliance and the terminal distribution service provider can achieve profit coordination.

It is proved as follows.

Assume that the revenue sharing ratio of the terminal distribution service provider is $\theta_{3}$ and $0<\theta_{3}<1$, then the profit of the alliance is $\prod_{M E}=\left[p-C_{M}-C_{E}-(1-\right.$ $\left.\left.\theta_{3}\right) W_{T}\right] q-k s^{2}$, and the profit of the terminal distribution service provider is $\prod_{T}=\left[\left(1-\theta_{3}\right) W_{T}-C_{T}\right] q$.

When

$$
\begin{aligned}
p & =\frac{2 k Q_{0}+\left(2 \alpha k-\beta^{2}\right)\left(C_{M}+C_{E}+C_{T}\right)}{4 \alpha k-\beta^{2}}, \\
s & =\frac{\beta\left[Q_{0}-\alpha\left(C_{M}+C_{E}+C_{T}\right)\right]}{4 \alpha k-\beta^{2}}, \\
W_{T} & =\frac{2 k\left[Q_{0}-\alpha\left(C_{M}+C_{E}\right)\right]+\left(6 \alpha k-\beta^{2}\right) C_{T}}{8 \alpha k-\beta^{2}},
\end{aligned}
$$

then

$$
\begin{aligned}
\prod_{M E}= & \frac{k\left[Q_{0}-\alpha\left(C_{M}+C_{E}+C_{T}\right)\right]}{\left(4 \alpha k-\beta^{2}\right)\left(8 \alpha k-\beta^{2}\right)}\left\{\left[4 \alpha k\left(1+\theta_{3}\right)-\beta^{2}\right]\right. \\
& \left.\cdot\left[Q_{0}-\alpha\left(C_{M}+C_{E}\right)\right]+\alpha\left[4 \alpha k\left(3 \theta_{3}-1\right)+\left(1-2 \theta_{3}\right) C_{T}\right]\right\}, \\
\prod_{T}= & \frac{2 k\left(1-\theta_{3}\right)\left[Q_{0}-\alpha\left(C_{M}+C_{E}\right)\right]+\left[2 \alpha k\left(1-3 \theta_{3}\right)-\theta_{3} \beta^{2}\right] C_{T}}{\left(4 \alpha k-\beta^{2}\right)\left(8 \alpha k-\beta^{2}\right)} \\
& \cdot\left[Q_{0}-\alpha\left(C_{M}+C_{E}+C_{T}\right)\right] .
\end{aligned}
$$

Since

$$
\begin{aligned}
& \frac{k\left[Q_{0}-\alpha\left(C_{M}+C_{E}+C_{T}\right)\right]^{2}}{8 \alpha k-\beta^{2}} \leq \prod_{M E} \leq \frac{k\left(48 \alpha^{2} k^{2}-12 \alpha k \beta^{2}+\beta^{4}\right)\left[Q_{0}-\alpha\left(C_{M}+C_{E}+C_{T}\right)\right]^{2}}{\left(8 \alpha k-\beta^{2}\right)^{2}\left(4 \alpha k-\beta^{2}\right)}, \\
& \frac{4 \alpha k^{2}\left[Q_{0}-\alpha\left(C_{M}+C_{E}+C_{T}\right)\right]^{2}}{\left(8 \alpha k-\beta^{2}\right)^{2}} \leq \prod_{T} \leq \frac{4 \alpha k^{2}\left[Q_{0}-\alpha\left(C_{M}+C_{E}+C_{T}\right)\right]^{2}}{\left(8 \alpha k-\beta^{2}\right)\left(4 \alpha k-\beta^{2}\right)},
\end{aligned}
$$

hence

$$
0<\theta_{3} \leq \frac{8 \alpha k^{2}\left[Q_{0}-\alpha\left(C_{M}+C_{E}+C_{T}\right)\right]}{\left(8 \alpha k-\beta^{2}\right)\left\{2 k\left[Q_{0}-\alpha\left(C_{M}+C_{E}\right)\right]+\left(6 \alpha k-\beta^{2}\right) C_{T}\right\}}
$$

\subsubsection{Cost Sharing Coordination of Semicentralized Model 2}

Proposition 17. In order to determine the centralized decision-making sales price $p$ and the express service effort level $s$, the service unit price of the terminal distribution service provider $W_{T}$ remains unchanged; it is assumed that the 
bearing ratio of the logistics service effort cost by the terminal distribution service provider is $\eta_{3}, 0<\eta_{3}<1$, then when $0<\eta_{3} \leq\left(16 \alpha^{2} k^{2}\left(4 \alpha k-\beta^{2}\right) /\left(8 \alpha k-\beta^{2}\right)^{2} \beta^{2}\right)$, the alliance and the terminal distribution service provider can achieve the profit coordination.

It is proved in the following.

Assume that the cost sharing ratio of logistics service effort by the terminal distribution service provider is $\eta_{3}$ and $0<\eta_{3}<1$, then the profit of the alliance is $\prod_{M E}=\left(p-C_{M}-C_{E}-W_{T}\right) q-\left(1-\eta_{3}\right) k s^{2}$, and the profit of the terminal distribution service provider is $\prod_{T}=\left(W_{T}-C_{T}\right) q-\eta_{3} k s^{2}$.

When

$$
\begin{gathered}
p=\frac{2 k Q_{0}+\left(2 \alpha k-\beta^{2}\right)\left(C_{M}+C_{E}+C_{T}\right)}{4 \alpha k-\beta^{2}}, \\
s=\frac{\beta\left[Q_{0}-\alpha\left(C_{M}+C_{E}+C_{T}\right)\right]}{4 \alpha k-\beta^{2}}, \\
W_{T}=\frac{2 k\left[Q_{0}-\alpha\left(C_{M}+C_{E}\right)\right]+\left(6 \alpha k-\beta^{2}\right) C_{T}}{8 \alpha k-\beta^{2}},
\end{gathered}
$$

then

$$
\begin{aligned}
\prod_{M E}= & \frac{k\left[Q_{0}-\alpha\left(C_{M}+C_{E}+C_{T}\right)\right]^{2}}{\left(4 \alpha k-\beta^{2}\right)^{2}\left(8 \alpha k-\beta^{2}\right)}\left[\left(4 \alpha k-\beta^{2}\right)^{2}\right. \\
& \left.+\eta_{3} \beta^{2}\left(8 \alpha k-\beta^{2}\right)\right], \\
\prod_{T}= & \frac{k\left[Q_{0}-\alpha\left(C_{M}+C_{E}+C_{T}\right)\right]^{2}}{\left(4 \alpha k-\beta^{2}\right)\left(8 \alpha k-\beta^{2}\right)}\left[4 \alpha k\left(4 \alpha k-\beta^{2}\right)\right. \\
& \left.-\eta_{3} b^{2}\left(8 \alpha k-\beta^{2}\right)\right] .
\end{aligned}
$$

Since

$$
\begin{aligned}
\frac{k\left[Q_{0}-\alpha\left(C_{M}+C_{E}+C_{T}\right)\right]^{2}}{8 \alpha k-\beta^{2}} & \leq \prod_{M E} \leq \frac{k\left(48 \alpha^{2} k^{2}-12 \alpha k \beta^{2}+\beta^{4}\right)\left[Q_{0}-\alpha\left(C_{M}+C_{E}+C_{T}\right)\right]^{2}}{\left(8 \alpha k-\beta^{2}\right)^{2}\left(4 \alpha k-\beta^{2}\right)}, \\
\frac{4 \alpha k^{2}\left[Q_{0}-\alpha\left(C_{M}+C_{E}+C_{T}\right)\right]^{2}}{\left(8 \alpha k-\beta^{2}\right)^{2}} & \leq \prod_{T} \leq \frac{4 \alpha k^{2}\left[Q_{0}-\alpha\left(C_{M}+C_{E}+C_{T}\right)\right]^{2}}{\left(8 \alpha k-\beta^{2}\right)\left(4 \alpha k-\beta^{2}\right)},
\end{aligned}
$$

then

$$
0<\eta_{3} \leq \frac{16 \alpha^{2} k^{2}\left(4 \alpha k-\beta^{2}\right)}{\left(8 \alpha k-\beta^{2}\right)^{2} \beta^{2}} .
$$

5.4. Summary of Coordination Schemes. According to the above analysis in this section, this study develops the corresponding coordination schemes for semicentralized models 1 and 2 . For semicentralized model 1 , there are three coordination strategies if $3 \beta^{2}-4 \alpha k>0$. Otherwise, there are four coordination strategies. For semicentralized model 2, there are two coordination strategies, which can lead to the win-win status.

\section{Numerical Analysis}

It is assumed that an E-commerce logistics market includes an E-commerce mall $M$, an express company $E$, and a terminal distribution service provider $T$. The E-commerce mall only sells one product, and the market demand function of the product is $q=450-8 p+15 s$. The logistics service cost of express company is $g(s)=16 s^{2}$. It is assumed that the unit product cost of E-commerce mall $C_{M}$ is 30 , the unit service cost of express company $C_{E}$ is 12 , and the unit distribution cost of terminal distribution service provider $C_{T}$ is 3 .

6.1. Numerical Analysis of Centralized and Semicentralized Decision Models. Take the above data into Table 3 and get the optimal solution and profit of each partner in semicentralized decision-making and centralized decisionmaking models, respectively (see Table 4).

Compared with the three semicentralized decisionmaking models, the logistics service quality of the express companies is higher, the price of products is lower, and the sales volume is higher, so the overall profit of the system is higher under the centralized decision-making model. Furthermore, semicentralized models 1 and 3 have the same effort level of logistics service, product price, and sales volume, thus bringing the same overall profit of the system. In the case of semicentralized model 2, the effort level of logistics service is low, the product price is high, and the sales volume is low, so the overall profit of the system is low. However, due to the fact that the E-commerce mall cannot control the effort level of logistics service when the express company and the terminal distribution service provider are in an alliance, and it is difficult to solve the practical problem that the end distribution cannot meet the customer demand. 


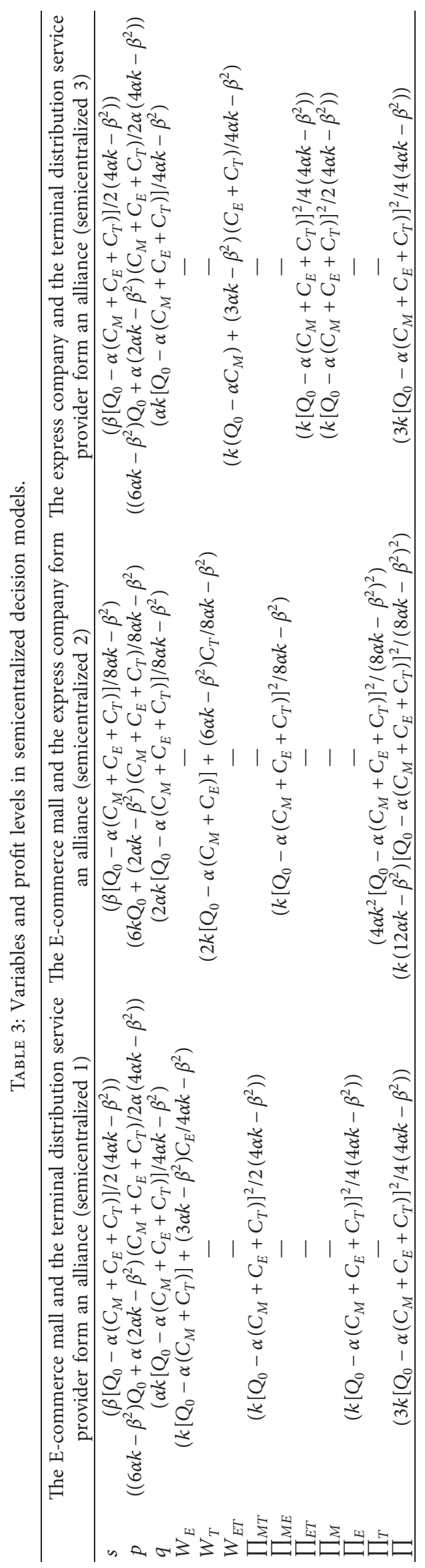


TABLE 4: Optimal solution and profit with different decision models.

\begin{tabular}{lcccc}
\hline Parameter & Semicentralized 1 & Semicentralized 2 & Semicentralized 3 & Centralized decision-making \\
\hline$s$ & 2.35 & 1.69 & 2.35 & 4.70 \\
$p$ & 55.64 & 55.81 & 55.64 & 55.03 \\
$q$ & 40.14 & 28.84 & 40.14 & \\
$W_{E}$ & 17.02 & & & \\
$W_{T}$ & & 6.60 & 20.17 & 225.78 \\
$W_{E T}$ & & & & \\
$\prod_{M}$ & 112.89 & & & \\
$\prod_{E}$ & & 103.94 & & \\
$\prod_{T}$ & 225.78 & & & \\
$\prod_{M T}$ & & 162.20 & 338.67 & \\
$\prod_{M E}$ & 338.67 & 266.14 & & \\
$\prod_{E T}$ & & & & \\
$\prod$ & & & & \\
\hline
\end{tabular}

Therefore, the alliance between the E-commerce mall and the express company or the terminal distribution service provider is the key to solve the logistics service quality and improve the logistics service. Compared with the alliance of E-commerce mall and the express company, the alliance of E-commerce mall and terminal distribution service provider has a higher effort level of logistics service, lower product price, and higher overall profit of the system.

To maximize the overall profit of the LSSC including the E-commerce mall, the express company, and the terminal distribution service provider, the express company should work harder so as to help the E-commerce mall obtain more orders, but its cost would increase. Therefore, it is necessary for all partners involved to cooperate on the basis of contract coordination so as to achieve all-win situation.

\subsection{Numerical Analysis Based on Coordination Schemes}

6.2.1. Numerical Analysis of Semicentralized Model 1. According to the analysis of Section 5 , if $3 \beta^{2}-4 \alpha k>0$, then there are three coordination schemes: (1) the alliance transfers part of the profit to the express company, (2) the alliance bears some logistics service cost of the express company, and (3) the alliance increases the unit delivery price of the express company.

A1: Coordination of Revenue Sharing. Taking the above data into formula (47), then.0.0145 $\leq \theta_{1} \leq 0.040$

That is, when the transferring ratio is within the interval $[0.0145,0.040]$, the profit of both parties can be coordinated and the profit of centralized decision-making can be achieved. The higher the transferring ratio, the less the profit it will earn. Otherwise, the alliance will get a higher profit. The specific transferring ratio depends on the negotiations between the two partners. The profit that can be realized by the two parties under different transfer ratios is shown in Table 5.

From Table 5 and Figure 1, it can be seen that the lower the proportion of revenue sharing by the alliance is, and the higher the profit of the alliance is. However, in any case, the total profits of the alliance and the express company are higher than the profits before the agreement of the contract
TABle 5: Coordination results of revenue sharing in semicentralized model 1 .

\begin{tabular}{lcccc}
\hline Parameter & Alliance & \multicolumn{3}{c}{ Profit coordination } \\
\hline$s$ & 2.35 & & 4.70 & \\
$p$ & 55.64 & & 55.03 & \\
$q$ & 40.14 & & 80.28 & \\
$W_{E}$ & 17.02 & & 17.02 & \\
$\theta_{1}$ & - & 0.02 & 0.025 & 0.035 \\
$\prod_{M T}$ & 225.78 & 313.85 & 291.76 & 247.58 \\
$\prod_{E}$ & 112.89 & 137.92 & 160.01 & 204.19 \\
$\prod$ & 338.67 & 451.77 & 451.77 & 451.77 \\
\hline
\end{tabular}

coordination scheme, which implies that the contract coordination scheme of revenue sharing can play an effective role.

B1: Coordination of Cost Sharing. Bringing the above data into formula (51), then $0.18 \leq \eta_{1} \leq 0.5$.

That is, the alliance, including the E-commerce mall and the terminal distribution service provider, bears the range of the effort cost of the express company within the interval $[0.18,0.5]$, and the coordination of the profit of both parties can be realized within the range. The specific cost range depends on the negotiations between the two parties. The profit that can be realized by both parties under different sharing ranges is shown in Table 6.

It can be seen from Table 6 and Figure 2 that the lower the proportion of cost sharing by the alliance is, the higher the profit of the alliance is. However, in any case, the total profits of the alliance and express companies are higher than the profits before the contract coordination scheme is reached, which shows that the contract coordination scheme can help the whole system achieve the all-win situation.

C1: Coordination of the Unit Price of Express Service. Bringing the above values into formula (55), then $0.047 \leq \varphi_{1} \leq 0.13$.

That is, the range of the unit price increase ratio of the express service is located in [0.047, 0.13], and the coordination of the profit of both parties can be realized within the range. The proportion of specific upward adjustment depends on the 


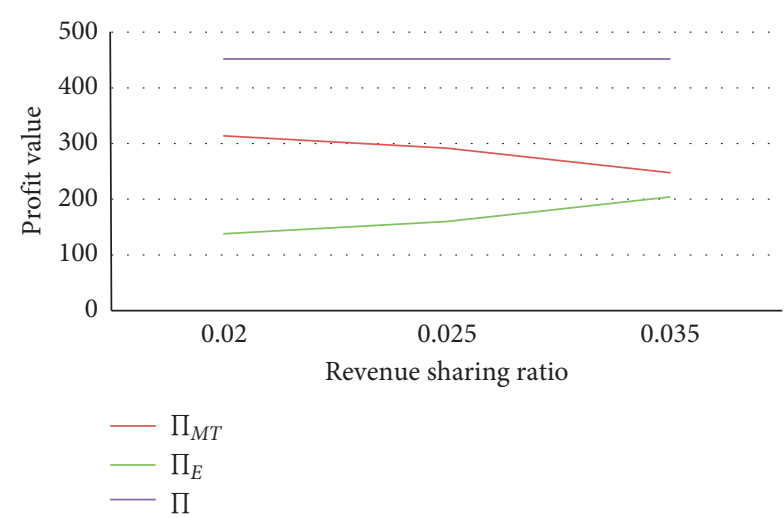

FIGURE 1: Sensitivity of revenue sharing in semicentralized model 1 .

TABLE 6: Coordination results of cost sharing in semicentralized model 1 .

\begin{tabular}{lcccc}
\hline Parameter & Alliance & \multicolumn{3}{c}{ Profit coordination } \\
\hline$s$ & 2.35 & & 4.70 & \\
$p$ & 55.64 & & 55.03 & \\
$q$ & 40.14 & & 80.28 & \\
$W_{E}$ & 17.02 & & 17.02 & \\
$\eta_{1}$ & - & 0.2 & 0.3 & 0.4 \\
$\prod_{M T}$ & 225.78 & 331.51 & 296.17 & 260.83 \\
$\prod_{E}$ & 112.89 & 120.26 & 155.60 & 190.94 \\
$\prod$ & 338.67 & 451.77 & 451.77 & 451.77 \\
\hline
\end{tabular}

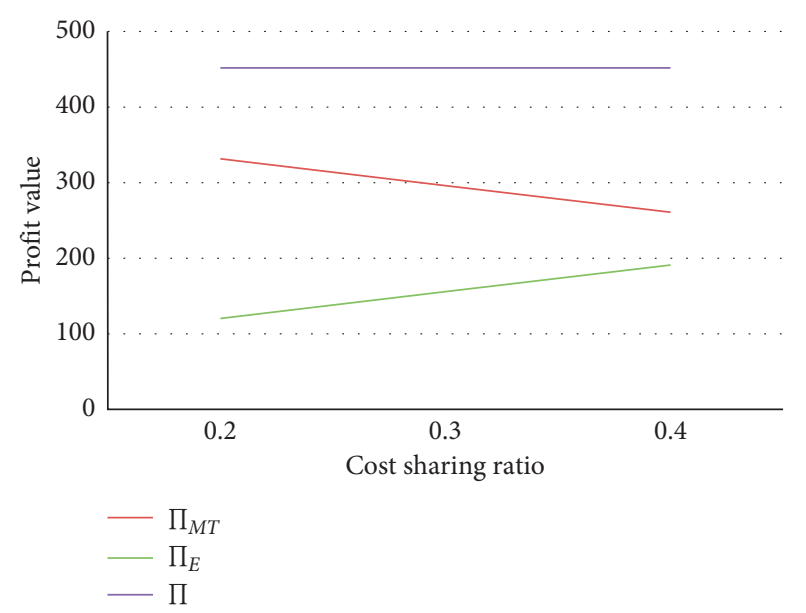

FIGURE 2: Sensitivity of cost sharing in semicentralized model 1.

results of negotiations between the two parties. The profits that can be realized by the two parties under different upward adjustment ratios are shown in Table 7.

From Table 7 and Figure 3, it can be seen that the lower the proportion of increasing the unit delivery price of the express company is, the higher the profit of the alliance is. However, in any case, the total profits of the alliance and the express company are higher than the profits before the contract coordination plan is reached, which shows that the contract coordination can make all the partners in the LSSC achieve the win-win status.
TABLE 7: Coordination result of the unit price of express service in semicentralized model 1 .

\begin{tabular}{lcccc}
\hline Parameter & Alliance & \multicolumn{3}{c}{ Profit coordination } \\
\hline$s$ & 2.35 & & 4.70 & \\
$p$ & 55.64 & & 55.03 & \\
$q$ & 40.14 & & 80.28 & \\
$W_{E}$ & 17.02 & 18.04 & 18.38 & 18.72 \\
$\varphi_{1}$ & - & 0.06 & 0.08 & 0.10 \\
$\prod_{M T}$ & 225.78 & 320.22 & 292.89 & 265.57 \\
$\prod_{E}$ & 112.89 & 131.55 & 158.88 & 186.20 \\
$\prod$ & 338.67 & 451.77 & 451.77 & 451.77 \\
\hline
\end{tabular}

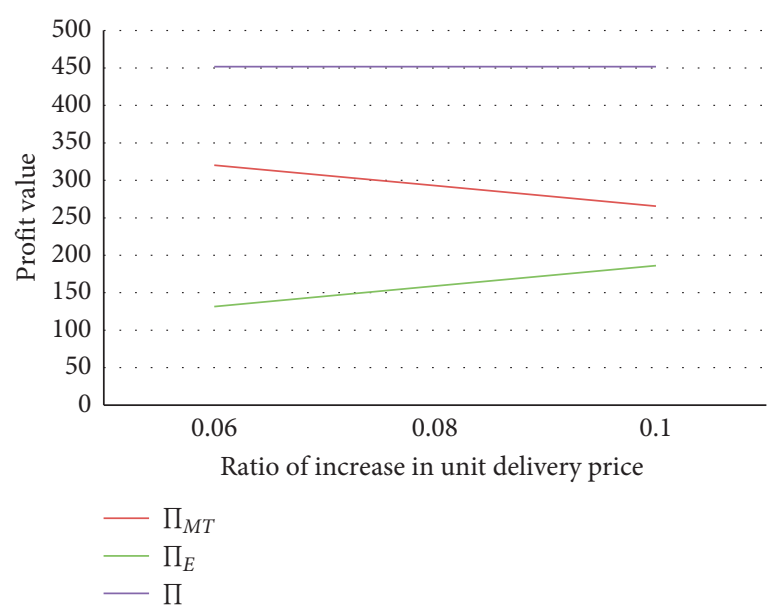

FIGURE 3: Sensitivity of the unit delivery price in semicentralized model 1 .

\subsubsection{Numerical Analysis of Semicentralized Model 2}

A3: Coordination of Revenue Sharing by the Terminal Distribution Service Provider. Take the above data into Formula (68), then $0<\theta_{3} \leq 0.35$.

That is, if the revenue sharing ratio of the terminal distribution service provider with the alliance is within the range of $(0,0.35]$, then all the partners can achieve the allwin situation. The specific ratio depends on the outcome of the negotiations between the two parties. The profit between the two parties with different ratios is shown in Table 8.

From Table 8 and Figure 4, it can be seen that the overall profit of the supply chain can be greatly improved, with an increase rate of $69.75 \%$ after the revenue sharing by the terminal distribution service provider. Furthermore, the smaller the proportion of revenue shared by the terminal distribution service provider is, the higher the profit of the terminal distribution service provider is. However, in any case, the total profits of the alliance and the terminal distribution service provider are higher than the profits before the contract coordination scheme is reached, which shows that the contract coordination scheme can lead to the all-win status.

B3: Coordination of Cost Sharing by the Terminal Distribution Service Provider. Bringing the above data into formula (72), then $0<\eta_{3} \leq 0.52$. 
TABle 8: Coordination results of revenue sharing in semicentralized model 2.

\begin{tabular}{lcccc}
\hline Parameter & Alliance & \multicolumn{3}{c}{ Profit coordination } \\
\hline$s$ & 1.69 & & 4.70 & \\
$p$ & 55.81 & & 55.03 & \\
$q$ & 28.84 & & 80.28 & \\
$W_{T}$ & 6.60 & 5.94 & 5.28 & 4.62 \\
$\theta_{3}$ & - & 0.1 & 0.2 & 0.3 \\
$\prod_{M E}$ & 162.20 & 215.75 & 268.73 & 321.71 \\
$\prod_{T}$ & 103.94 & 236.02 & 183.04 & 130.06 \\
$\prod$ & 266.14 & 451.77 & 451.77 & 451.77 \\
\hline
\end{tabular}

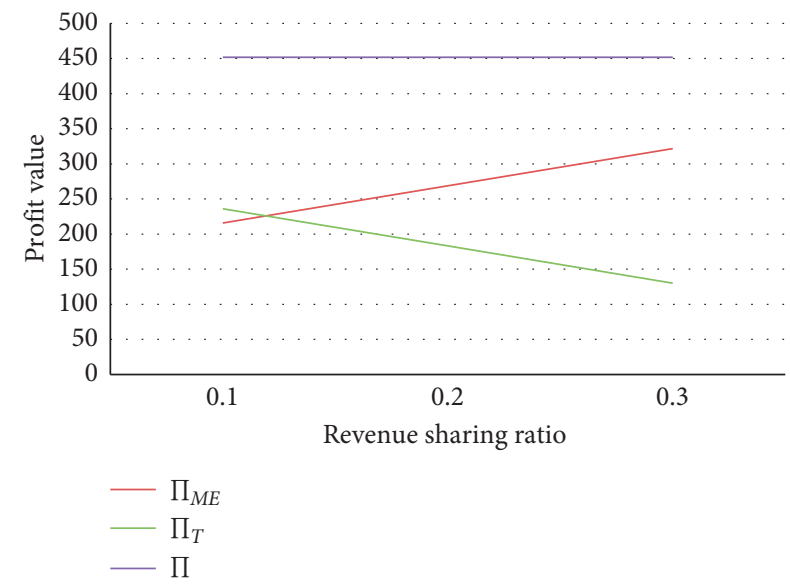

FIGURE 4: Sensitivity of revenue sharing in semicentralized model 2.

TABLE 9: Coordination results of cost sharing in semicentralized model 2.

\begin{tabular}{lcccc}
\hline Parameter & Alliance & \multicolumn{3}{c}{ Profit coordination } \\
\hline$s$ & 1.69 & & 4.70 & \\
$p$ & 55.81 & & 55.03 & \\
$q$ & 28.84 & & 80.28 & \\
$W_{T}$ & 6.60 & & 6.60 & \\
$\eta_{3}$ & - & 0.1 & 0.3 & 0.45 \\
$\prod_{M E}$ & 162.20 & 198.10 & 268.79 & 321.81 \\
$\prod_{T}$ & 103.94 & 253.67 & 182.98 & 129.96 \\
$\prod$ & 266.14 & 451.77 & 451.77 & 451.77 \\
\hline
\end{tabular}

That is, the terminal distribution service provider undertakes some percentage of the service effort cost. If the ratio ranges within the interval of $(0,0.52]$, then the coordination can be realized. The specific cost-bearing ratio depends on the results of negotiation between the two sides. The profits realized by the two sides under different share ratios are shown in Table 9.

From Table 9 and Figure 5, it can be seen that the overall profit of the supply chain can also be greatly improved, with an increase of $69.75 \%$ after the cost sharing by the terminal distribution service provider. Specifically, the smaller the bearing proportion of effort cost by the terminal distribution service provider is, the higher the profit of the terminal distribution service provider is. However, in any case, the total profits of the alliance and the terminal distribution

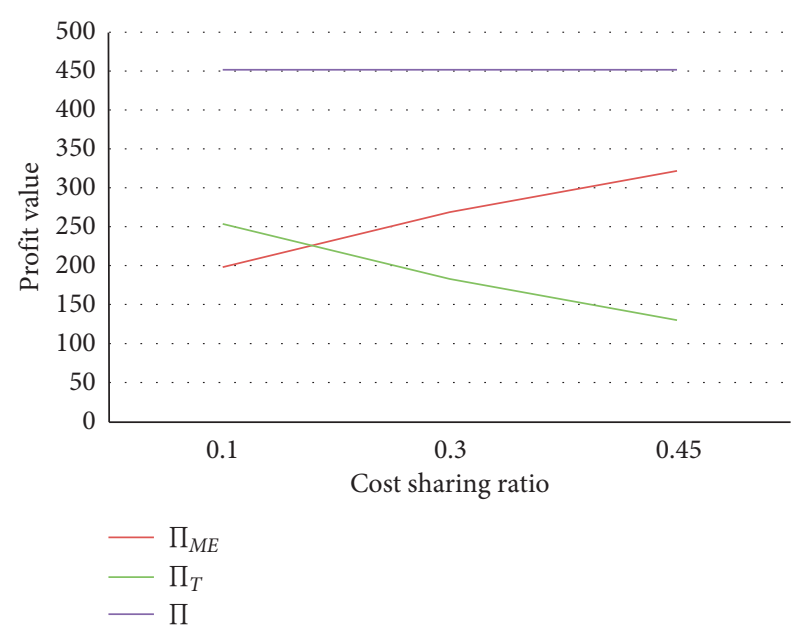

Figure 5: Sensitivity of cost sharing in semicentralized model 2.

service provider are higher than the profits before the contract coordination scheme is reached, which suggests that the contract coordination scheme can stimulate all the partners to cooperate together and get the win-win situation.

\section{Conclusion and Future Research}

This study focuses on the E-commerce LSSC system consisting of an E-commerce mall, an express company, and a terminal distribution service provider and studies the coordination strategy of semicentralized and centralized decision models. With comparative analysis, it is found that the performance of the centralized model is better than that of semicentralized models.

To achieve the global profit level of centralized decisionmaking and promote the cooperation to establish alliances, it is necessary to apply coordination strategies to achieve longterm win-win cooperation. Based on this, it discusses the profit coordination schemes of the two semicentralized alliances. In the profit coordination scheme of the semicentralized model 1 , coordination strategies are discussed according to the two situations. When $3 \beta^{2}-4 \alpha k>0$, three coordination strategies are discussed: revenue sharing, cost sharing, and coordination of the unit delivery price. When $4 \alpha k-3 \beta^{2}>0$, four coordination strategies are proposed: the alliance's revenue sharing, cost sharing, coordination of the unit delivery price, and the express company's revenue sharing. In the coordination scheme of semicentralized model 2, two coordination schemes are developed, which are the strategy of revenue sharing and cost sharing by the terminal distribution service provider.

Furthermore, through the numerical analysis, the revenue transferring ratio, the proportion of cost sharing, and the unit delivery price of logistics service under the semicentralized decision models are analyzed, respectively. Under the coordination strategy, the ratios of revenue sharing and cost sharing are different in the above semicentralized decision models. The choice of specific contract scheme depends on the comparative advantage of each partner in the negotiation. The research results also provide 
some practical support for decision makers to choose appropriate cooperation models based on their real business environment.

Finally, it concludes that the E-commerce mall can get the highest profit when the express company and the terminal distribution service provider join the alliance. However, the E-commerce business may not be sustainable because the E-commerce mall cannot control the logistics service quality and cannot solve the bottleneck problem of the last-mile delivery in reality, which is a key issue for customers. The alliance of E-commerce mall and terminal distribution service providers can improve the quality of logistics service, solve the bottleneck problem of terminal distribution, and improve the overall profit of LSSC. E-commerce mall and terminal distribution service providers can join the alliance with express companies through supply chain coordination, such as revenue sharing, cost sharing, and adjusting the unit delivery price. When the E-commerce mall and express company join the alliance, we need to coordinate the terminal distribution service provider to share some revenue or undertake some cost of logistics service so as to make all the partners achieve the all-win status. Therefore, for E-commerce LSSC, the alliance including E-commerce mall and terminal distribution service providers can be a better choice. The rookie alliance in real life is a typical embodiment.

This research, with respect to existing studies, extends the supply chain coordination in the field of downstream three-echelon LSSC including the terminal distribution, takes the price and effort level of logistics service dependent demand into account, develops effective coordination strategies, such as revenue sharing and cost sharing contracts, and unit delivery price coordination, and provides managerial implication for decision makers to choose appropriate alliance in real business and develop effective coordination strategy.

However, there also exist the following limitations. (1) In real business, the price and demand functions are affected by many factors and are not simply linear or quadratic functions. In the subsequent research, the influences of various factors on price and demand will be considered to establish more practical decision models. (2) In the supply chains with both online and offline business, the sales volume of online platform will be fluctuated by the influence of offline sales. The future research will explore the problem with stochastic demand and information asymmetry and consider the decision-making with a dual-channel online and offline business.

\section{Data Availability}

The data used to support the findings of this study are included within the article.

\section{Conflicts of Interest}

The authors declare that there are no conflicts of interest regarding the publication of this paper.

\section{Acknowledgments}

This study was supported by Humanities and Social Sciences foundation of Ministry of Education in China (Grant 17YJC630230), Social Sciences Federation of Guangdong in China (Grant GD17XGL11), and Macau University of Science and Technology Foundation (Grant FRG-19-033MSB).

\section{References}

[1] D. A. Hensher, Z. Y. Zhang, and J. Rose, "Transport and logistics challenges for China: drivers of growth, and bottlenecks constraining development," Road \& Transport Research, vol. 24, no. 2, pp. 32-41, 2015.

[2] J. J. Spengler, "Vertical integration and antitrust policy," Journal of Political Economy, vol. 58, no. 4, Article ID 347e352, 1950.

[3] J. Xie, W. Zhang, L. Liang, Y. Xia, J. Yin, and G. Yang, "The revenue and cost sharing contract of pricing and servicing policies in a dual-channel closed-loop supply chain," Journal of Cleaner Production, vol. 191, pp. 361-383, 2018.

[4] J. Luo and X. Chen, "Coordination of random yield supply chains with improved revenue sharing contracts," European Journal of Industrial Engineering, vol. 10, no. 1, pp. 81-102, 2016.

[5] H. Zhao, S. Song, Y. Zhang, J. N. D. Gupta, A. G. Devlin, and R. Chiong, "Supply chain coordination with a risk-averse retailer and a combined buy-back and revenue sharing contract," Asia-Pacific Journal of Operational Research, vol. 36, no. 5, Article ID 1950028, 2019.

[6] Z. H. Wu, L. C. Feng, and D. Y. Chen, "Coordinating pricing and advertising decisions for supply chain under consignment contract in the dynamic setting," Complexity, vol. 2018, Article ID 7697180, 11 pages, 2018.

[7] H. Song and X. Gao, "Green supply chain game model and analysis under revenue-sharing contract," Journal of Cleaner Production, vol. 170, pp. 183-192, 2018.

[8] N. Yan, Y. Liu, X. Xu, and X. He, "Strategic dual-channel pricing games with e-retailer finance," European Journal of Operational Research, vol. 283, no. 1, pp. 138-151, 2020.

[9] M. Hua, I. K. W. Lai, and H. Tang, "Analysis of advertising and a points-exchange incentive in a reverse supply chain for unwanted medications in households based on Game Theory," International Journal of Production Economics, vol. 217, pp. 259-268, 2019.

[10] M. N. Hua, H. J. Tang, and I. K. W. Lai, "Game theoretic analysis of pricing and cooperative advertising in a reverse supply chain for unwanted medications in households," Sustainability, vol. 9, no. 10, 2017.

[11] Q. H. Pang, Y. E. Chen, and Y. L. Hu, "Coordinating threelevel supply chain by revenue-sharing contract with sales effort dependent demand," Discrete Dynamics in Nature and Society, vol. 2014, Article ID 561081, 10 pages, 2014.

[12] Q. H. Pang, X. Y. Wu, and M. L. Tan, "Supply chain coordination using revenue-sharing contract with DISTRIBUTOR'S effort dependent demand," International Journal of Simulation Modelling, vol. 14, no. 2, pp. 335-348, 2015.

[13] A. A. Taleizadeh, N. Rabiei, and M. Noori-Daryan, "Coordination of a two-echelon supply chain in presence of market segmentation, credit payment, and quantity discount policies," International Transactions in Operational Research, vol. 26, no. 4, pp. 1576-1605, 2019. 
[14] S. Sang, "Revenue sharing contract in a multi-echelon supply chain with fuzzy demand and asymmetric information," International Journal of Computational Intelligence Systems, vol. 9, no. 6, pp. 1028-1040, 2016.

[15] J. Cai, X. Hu, P. R. Tadikamalla, and J. Shang, "Flexible contract design for VMI supply chain with service-sensitive demand: revenue-sharing and supplier subsidy," European Journal of Operational Research, vol. 261, no. 1, pp. 143-153, 2017.

[16] J. Zhao, J. Wei, and X. C. Sun, "Coordination of fuzzy closedloop supply chain with price dependent demand under symmetric and asymmetric information conditions," Annals of Operations Research, vol. 257, no. 1-2, pp. 469-489, 2017.

[17] L. M. Zhao, L. Li, Y. Song, C. Li, and Y. Wu, "Research on pricing and coordination strategy of a sustainable green supply chain with a capital-constrained retailer," Complexity, vol. 2018, Article ID 6845970, 12 pages, 2018.

[18] N. Yan, T. Tong, and H. Dai, "CAPITAL-CONSTRAINED supply chain with multiple decision attributes: decision optimization and coordination analysis," Journal of Industrial \& Management Optimization, vol. 15, no. 4, pp. 1831-1856, 2019.

[19] J. Zhang, G. Liu, Q. Zhang, and Z. Bai, “Coordinating a supply chain for deteriorating items with a revenue sharing and cooperative investment contract," Omega, vol. 56, pp. 37-49, 2015.

[20] Q. Bai, M. Chen, and L. Xu, "Revenue and promotional costsharing contract versus two-part tariff contract in coordinating sustainable supply chain systems with deteriorating items," International Journal of Production Economics, vol. 187, pp. 85-101, 2017.

[21] B. C. Giri, C. Mondal, and T. Maiti, "Analysing a closed-loop supply chain with selling price, warranty period and green sensitive consumer demand under revenue sharing contract," Journal of Cleaner Production, vol. 190, pp. 822-837, 2018.

[22] J. Heydari and M. Ghasemi, "A revenue sharing contract for reverse supply chain coordination under stochastic quality of returned products and uncertain remanufacturing capacity," Journal of Cleaner Production, vol. 197, pp. 607-615, 2018.

[23] H. Peng, T. Pang, and J. Cong, "Coordination contracts for a supply chain with yield uncertainty and low-carbon preference," Journal of Cleaner Production, vol. 205, pp. 291-302, 2018.

[24] H. Zou, J. Qin, P. Yang, and B. Dai, “A coordinated revenuesharing model for a sustainable closed-loop supply chain," Sustainability, vol. 10, no. 9, 2018.

[25] H. Mohammadi, M. Ghazanfari, M. S. Pishvaee, and E. Teimoury, "Fresh-product supply chain coordination and waste reduction using a revenue-and-preservation-technology-investment-sharing contract: a real-life case study," Journal of Cleaner Production, vol. 213, pp. 262-282, 2019.

[26] M. Ghazanfari, H. Mohammadi, M. S. Pishvaee, and E. Teimoury, "Fresh-product trade management under government-backed incentives: a case study of fresh flower market," Ieee Transactions on Engineering Management, vol. 66, no. 4, pp. 774-787, 2019.

[27] Y. G. Zhong, F. Guo, Z. Wang, and H. Tang, "Coordination analysis of revenue sharing in E-commerce logistics service supply chain with cooperative distribution," SAGE Open, vol. 9, no. 3, Article ID 215824401987053, 2019.

[28] Q. H. Pang, Y. L. Hou, and Y. F. Lv, “Coordinating three-level supply chain under disruptions using revenue-sharing contract with effort dependent demand," Mathematical Problems in Engineering, vol. 2016, Article ID 9167864, 10 pages, 2016.
[29] Y. Hou, F. Wei, S. X. Li, Z. Huang, and A. Ashley, "Coordination and performance analysis for a three-echelon supply chain with a revenue sharing contract," International Journal of Production Research, vol. 55, no. 1, pp. 202-227, 2017.

[30] Y. Yuan, S. Ju, Y. Fan, and W. Bian, "The revenue-sharing model of logistics service supply chain for online seafood retailing," Journal of Coastal Research, vol. 94, no. sp1, pp. 659-665, 2019.

[31] P. Liu and S. P. Yi, "Investment decision-making and coordination of a three-stage supply chain considering Data Company in the Big Data era," Annals of Operations Research, vol. 270, no. 1-2, pp. 255-271, 2018.

[32] B. C. Giri and B. R. Sarker, "Coordinating a multi-echelon supply chain under production disruption and price-sensitive stochastic demand," Journal of Industrial and Management Optimization, vol. 15, no. 4, pp. 1631-1651, 2019.

[33] X. F. Liu, J. Li, J. Wu, and G. Zhang, "Coordination of supply chain with a dominant retailer under government price regulation by revenue sharing contracts," Annals of Operations Research, vol. 257, no. 1-2, pp. 587-612, 2017.

[34] Q. F. Meng, J. X. Chen, and K. Qian, "The complexity and simulation of revenue sharing negotiation based on construction stakeholders," Complexity, vol. 2018, Article ID 5698170, 11 pages, 2018.

[35] A. Z. Zeng and J. Hou, "Procurement and coordination under imperfect quality and uncertain demand in reverse mobile phone supply chain," International Journal of Production Economics, vol. 209, pp. 346-359, 2019.

[36] F. Ye, Q. Lin, and Y. Li, "Coordination for contract farming supply chain with stochastic yield and demand under CVaR criterion," Operational Research, vol. 20, no. 1, pp. 369-397, 2020.

[37] J. Zhao, Y.-W. Zhou, Z.-H. Cao, and J. Min, "The shelf space and pricing strategies for a retailer-dominated supply chain with consignment based revenue sharing contracts," European Journal of Operational Research, vol. 280, no. 3, pp. 926-939, 2020.

[38] R. Yan and Z. Pei, "Retail services and firm profit in a dualchannel market," Journal of Retailing and Consumer Services, vol. 16, no. 4, pp. 306-314, 2009.

[39] W.-y. K. Chiang, D. Chhajed, and J. D. Hess, "Direct marketing, indirect profits: a strategic analysis of dual-channel supply-chain design," Management Science, vol. 49, no. 1, pp. 1-20, 2003

[40] W. Huang and J. M. Swaminathan, "Introduction of a second channel: implications for pricing and profits," European Journal of Operational Research, vol. 194, no. 1, pp. 258-279, 2009. 